\title{
Synthetic Approaches and Biological Significance of Oxazolone Moieties: A Review
}

\author{
Neelottama Kushwaha ${ }^{1, * \text { ID }, \text { Swatantra Kushwaha }}{ }^{2}$ (D) \\ 1 Department of Pharmacy, Pranveer Singh Institute of Technology, Kanpur-209305, India, neelottama@gmail.com (N.K.); \\ 2 Department of Pharmacy, Pranveer Singh Institute of Technology, Kanpur-209305, India, \\ swatantrakushwaha15@gmail.com (S.K.); \\ * Correspondence: neelottama@gmail.com(N.K.);
}

Scopus Author ID 36637519800

Received: 6.07.2021; Revised: 25.09.2021; Accepted: 29.09.2021; Published: 19.11.2021

\begin{abstract}
Oxazolone is a five-membered heterocyclic compound which is also known as azlactone. It contains one oxygen and one nitrogen as heteroatoms, which exist in five isomeric forms, according to the carbonyl group's location and the double bonds such as: 5 (4)-oxazolones, 5 (2) - oxazolones, 2 (3)oxazolones, 4 (5)-oxazolones, and 2 (5)-oxazolones. 5 (4)-oxazolones is the most important heterocyclic moiety among all isomeric form of oxazolones. It is classified into two classes: saturated and unsaturated oxazolones. It is synthesized by various synthetic routes. Oxazolones are reported to exhibit various pharmacological activities such as antimicrobial, anti-inflammatory, anticancer, antiHIV, antiangiogenic, anticonvulsant, sedative, cardiotonic, antidiabetic activity, etc.
\end{abstract}

Keywords: oxazolone; derivatives; activities; synthesis; use.

(C) 2021 by the authors. This article is an open-access article distributed under the terms and conditions of the Creative Commons Attribution (CC BY) license (https://creativecommons.org/licenses/by/4.0/).

\section{Introduction}

Oxazolones are a type of heterocyclic compounds that play a key role in the synthesis of a variety of tiny chemical molecules, such as amino alcohols [1], amino acids [2], thiamine [3], amides [4], peptides [5-8], and polyfunctional compounds [9]., derivatives possess important biological activities; such as antimicrobial [15-20], antitubercular [21], antiinflammatory [22-23], anticancer [24-28], anti-HIV [29-31], antiangiogenic [32], anticonvulsant [33], sedative [34-36], cardiotonic activity [37], antidiabetic [38], insecticidal activity [39] and antiulcer activity [40].

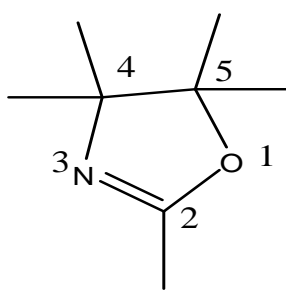

Oxazolines

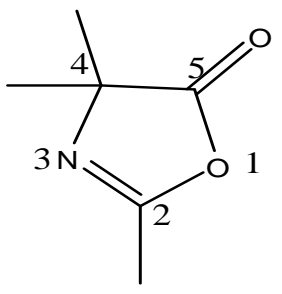

Oxazolones

Figure 1. Keto-derivative of oxazolines.

These are used as synthons for the construction of various alkaloid skeletons, heterocyclic precursors [41-44], immunomodulatory [45], and biosensors [46-48] or photosensitive composition devices for proteins [49-52]. Structurally, oxazolones (also known as azlactones or oxazol-5-(4 H) - ones) construct a class of five-membered heterocycles with 
one nitrogen and two oxygen atoms. Functionallysubstituted oxazolones have been recognized as efficient pharmacophores [53-56]. Some oxazolone has shown a wide range of pharmaceutical properties [57].

Oxazolones, classically Azlactones, are regarded as the keto-derivatives of oxazolines (Figure 1).

\section{Structure, Classification, and Nomenclature}

Since 1883, oxazolones have been produced in a variety of ways. These are fivemembered heterocyclic compounds with oxygen and nitrogen as heteroatoms that come in five isomeric forms depending on where the carbonyl group and double bonds are located, such as 5(4)-oxazolones. These have grown in relevance in recent years as a result of their pharmacological properties. The biological actions of oxazolone are determined by the $\mathrm{C}-2$ and C-4 locations.

Internal anhydrides of -acyl amino acids with a five-membered ring and Nitrogen and Oxygen as heteroatoms are known as oxyzolones. Unsaturated and saturated oxazolones are the two types of oxazolones. (Figure 2)

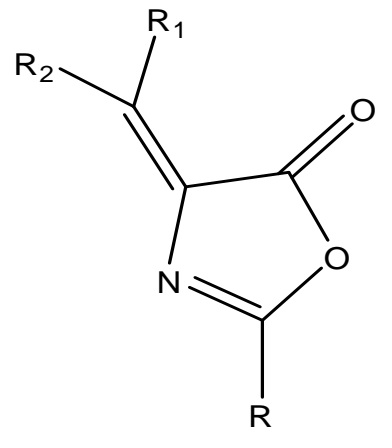

Unsaturated

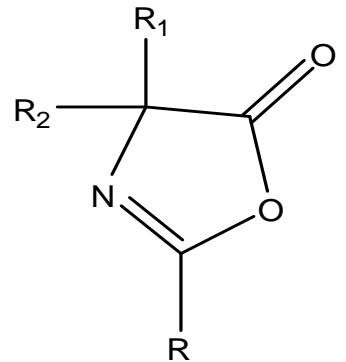

Saturated

Figure 2. Unsaturated and saturated form of oxazolones.

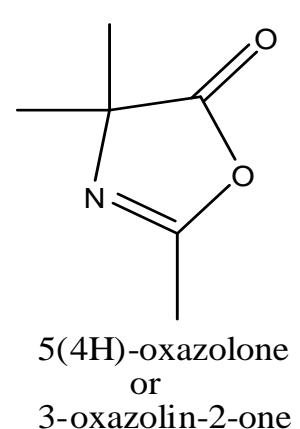

3-oxazolin-2-one

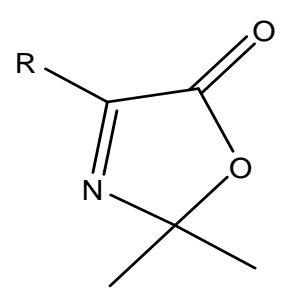

$5(2 \mathrm{H})-$ oxazolone or

3-oxazolin-5-one

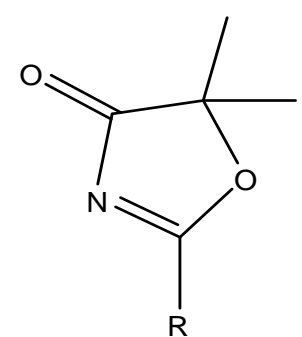

4(5H)-oxazolone 2-oxazolin-4-one

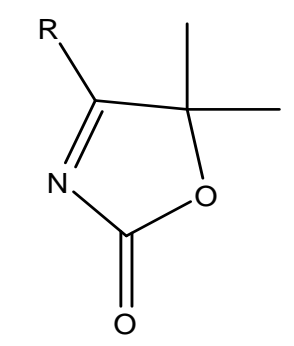

2(5H)-oxazolone or

3-oxazolin-2-one

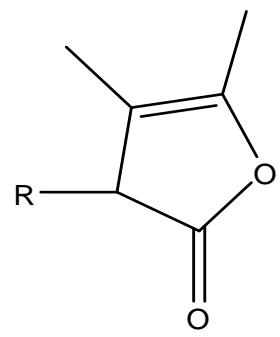

2(3H)-oxazolone

or

4-oxazolin-2-one

Figure 3. Types of oxazolones. 
Additionally, there are five different forms of oxazolones (Figure 3). The 5(4)oxazolones are a big and important group of chemicals among these. The 5(2) - oxazolones are made up of a small number of recently discovered compounds referred to as "Pseudo oxazolones. Several studies on 2(3)-systems have also been published, and the existence of 4(5)-systems, which was previously disputed, has now been shown. The 2(5)-oxazolones, on the other hand, were unknown.

\section{Chemistry}

The oxazole nucleus' derivative is oxazolone. The structures of various oxazoles have been established using the X-ray diffraction method. The oxazole ring's bond length () and angles are given in (Figure. 4). The bond length $(\AA)$ and angles of the oxazole ring are given in (Figure 4).

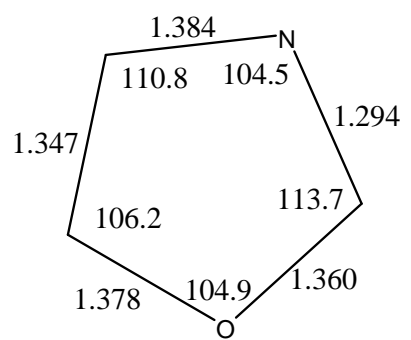

Figure 4. Bond length $(\AA)$ and angles of the oxazole ring.

The oxazole ring is planar, and the distances suggest that oxazole has a high degree of bond fixing, with a notable variation in the lengths of the $\mathrm{C}(2)-\mathrm{N}$ and $\mathrm{C}(4)-\mathrm{N}$ bonds.

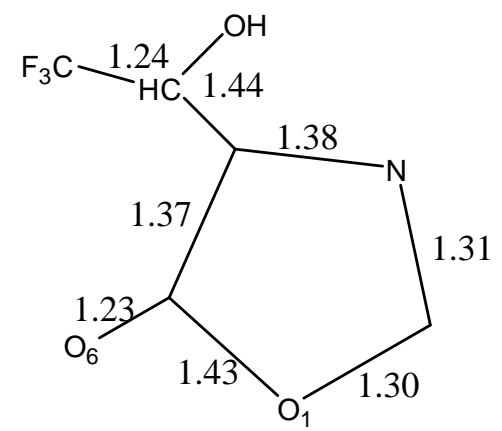

Figure 5. Bond length $(\AA)$ of the azlactone ring.

On the basis given (Figure 5) the exocyclic carbon-oxygen bond $\mathrm{C}(5)-\mathrm{O}(6)$ is short (1. $23 \AA$ ), like those lactones, whereas the $\mathrm{C}$ (5)-O (1) bond is much longer than the other bonds in the ring.

The action of oxazolone is dependent on the substitution of a functional group at C-4 and C-2 locations. The immunosuppressive effect of the oxazolone moiety with a substituted (p-nitro) exocyclic phenyl group at C-4 is considerably influenced [58]. The presence of a cinnamoyl residue at the $\mathrm{C}-4$ position of the oxazolone moiety, as well as the substitution of a functional group at the C-4 and C-2 locations of the oxazolone, is required for tyrosinase inhibitory action. An aliphatic double bond present at the $\mathrm{C}-4$ position of the oxazolone moiety and a phenyl ring present at C-2 plays a vital function in medicinal chemistry, according to (Figure 6) [59]. With an increase in the electron-donating characteristics of the phenyl ring substituent at the C-2 location, the rate of the oxazolone ring-opening reaction reduced [60]. Exocyclic double bonds can behave as dienophiles, and N-substituted oxazolone is involved in intermolecular Diels-Alder processes [61]. 


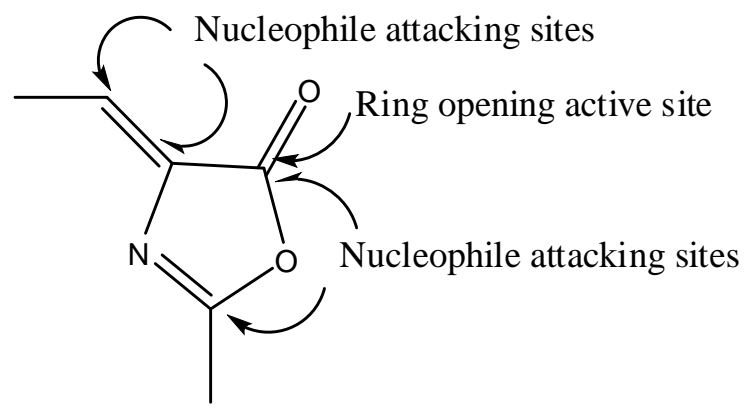

Figure 6. Active sites present on oxazolone.

Lewis acid activation of the carbonyl group of unsaturated oxazolones gives electrophilic character to the $\beta$-carbon [62].

Oxazole has a sextet of - electrons in its aromaticity; all of its features show that the delocalization is fairly incomplete; thus, it has little aromatic character. Bond fixation is high, hydroxy-oxazoles are unstable compared to their oxo tautomers, oxazoles operate as dienes in the Diels-Alder reaction, and electrophilic substitution is rare. The tendency of oxazolone to undergo ring-opening rather than maintaining its type dominates its chemistry.5(4H)Oxazolones, the saturated azlactones, have been studied intensively. They show carbonyl and $\mathrm{C}=\mathrm{N}$ absorptions in the 1820 and $1660 \mathrm{~cm}^{-1}$ regions, respectively. Azlactones derived from chiral $\alpha$ - amino acids can be obtained in optically active forms which racemize easily.

The chemistry of oxazolones is fascinating, as shown in (Figure 7) with a focus on $5(4 \mathrm{H})$ - Oxazolones (1). Some nucleophiles attack these compounds at C-2 (2), but fission of the carbonyl-oxygen link (3), which leads to a-amino acids or their derivatives, is more common. By way of the resonance stabilized anions (4), 5(4H)-oxazolones react with electrophiles at C-4 or, less typically, at C-2, and they can function as tautomeric 1,3-dipoles (5) in cycloaddition processes.<smiles>[R]C1=NCC(=O)O1</smiles>

(1)

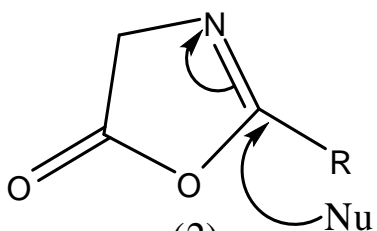

(2)

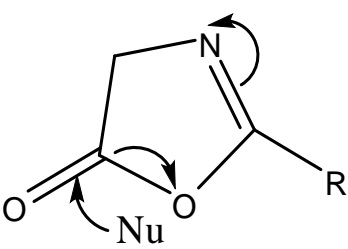

(3)

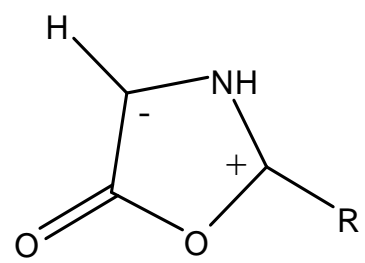

(5)

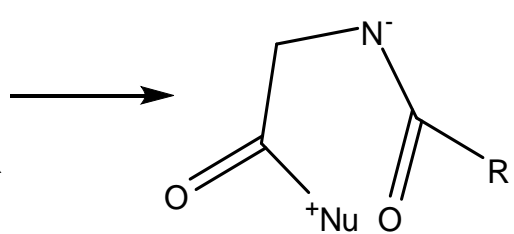

${ }^{+} \mathrm{Nu} O$

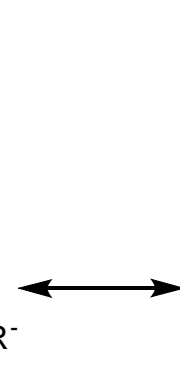

$-\mathrm{O}$<smiles>[2H]c1c(O)cc2nc1O2</smiles>

(4)

Figure 7. Chemistry of oxazolone. 


\section{Synthesis of Oxazolones}

There are various methods [63-66] available for the synthesis of oxazolones. Some well-known methods of synthesis are:

\section{Erlenmeyer Synthesis}

The Erlenmeyer reaction (Scheme 1) was initially described by Friedrich Gustav Carl Emil Erlenmeyer in 1893. In the presence of acetic anhydride and sodium acetate, condensation occurred between benzaldehyde and $\mathrm{N}$-acetyl glycine. Following the initial cyclization of the $\mathrm{N}$-acetyl glycine, the reaction undergoes a Perkin condensation, generating Erlenmeyer azlactones.

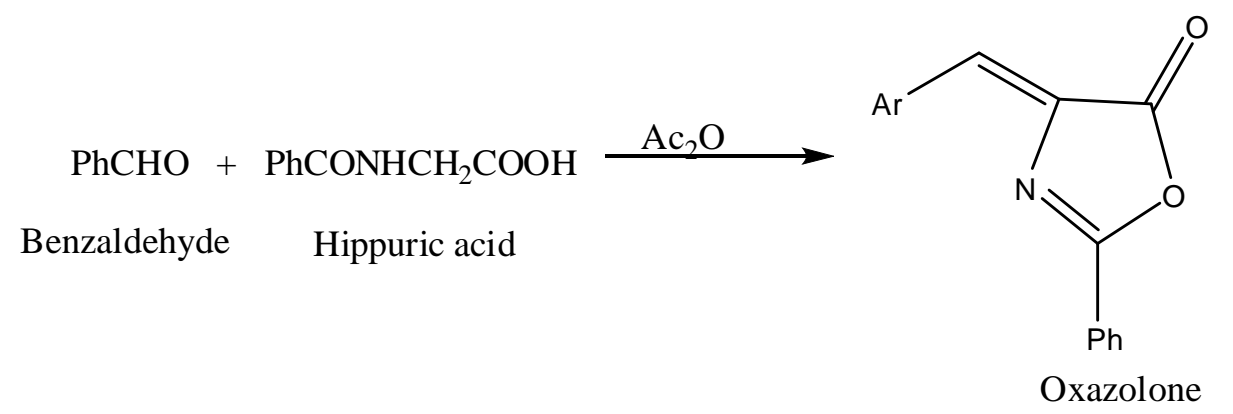

Scheme 1. Synthesis of Erlenmeyer azlactones.

The cyclodehydration condensation process is the earliest technique of producing oxazolone (Scheme 2). Oxazolone was created in this reaction by combining a carbonyl molecule, an acyl glycine, and acetic anhydride to produce 4-alkylidene-5(4)-oxazolone.

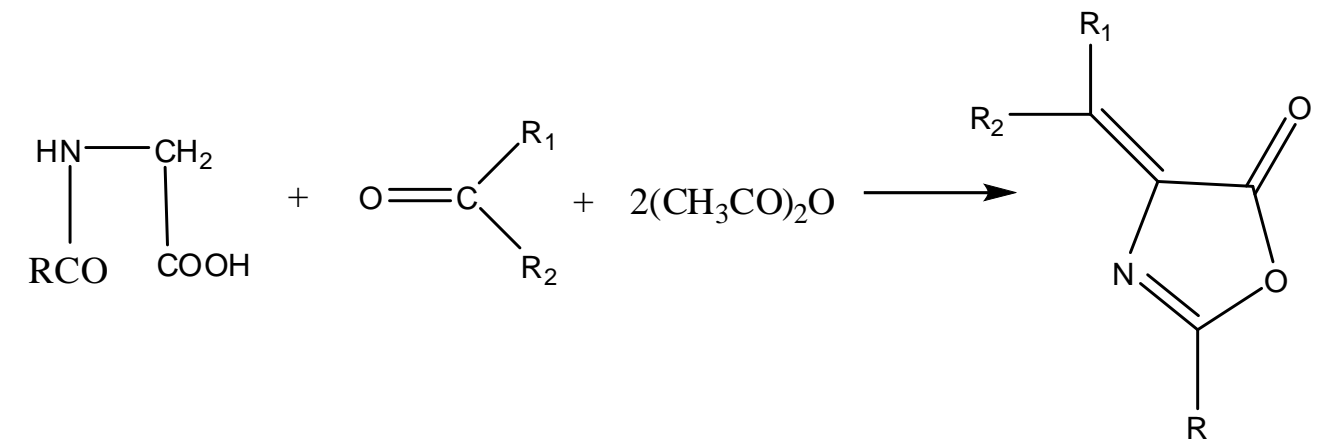

Scheme 2. Synthesis of oxazolone by cyclohydration condensation reaction.

Adding sodium acetate as a catalyst isn't always necessary. As a reagent, potassium carbonate [67] has also been utilized. Various acyl glycines, including those having the acetyl, benzoyl, and phenyl acetyl groups, have been utilized to make oxazolone. Hippuric acid (Nbenzoyl glycines) produces the highest yield and the most stable compounds of all of them. When sodium acetate is replaced with lead acetate in the condensation of acetaldehyde and certain aliphatic aldehydes with hippuric acid, the yield of the oxazolones is considerably enhanced [68], but this alteration has no effect on the benzaldehyde-hippuric acid condensation. The use of $\mathrm{SO}_{3}$ in DMF and polyphosphoric acid (PPA) is the other method available for the preparation of oxazolones [69] (Scheme $3 \& 4$ ). It is reported that PPA gives a better yield. However, the insolubility of several substrates in PPA makes the procedure less attractive. 


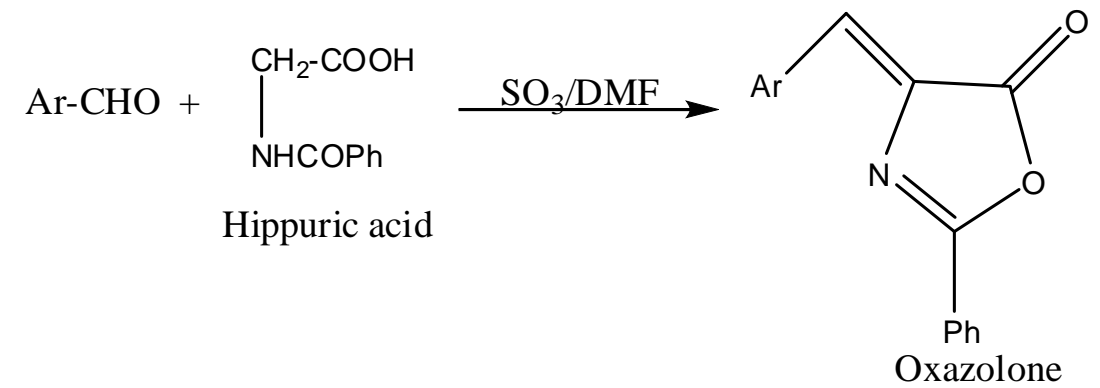

Scheme 3. Synthesis of oxazolone by using $\mathrm{SO}_{3}$ in $\mathrm{DMF}$.

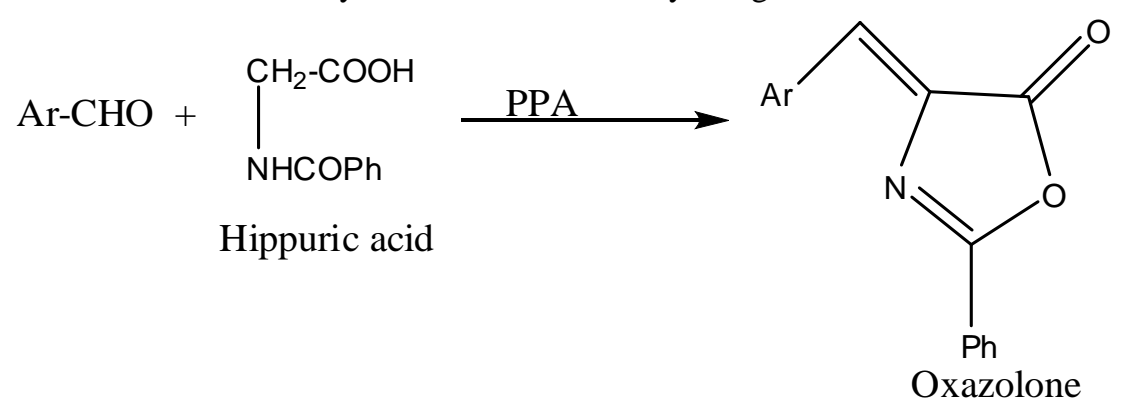

Scheme 4. Synthesis of oxazolone by using PPA.

The cyclodehydration-condensation of hippuric acid and aromatic carbonyls has also been described recently [70]. The reaction of various aromatic aldehydes with hippuric acid was effectively carried out using a 1:1 weight ratio of neutral alumina and boric acid in the presence of a stoichiometric quantity of acetic anhydride in a refluxing benzene or toluene solution to produce oxazolones. The yield of the oxazolone was reported to be 80-90 \%, and it was isolated using simple filtration to remove the solid $\mathrm{A}_{2} \mathrm{O}_{3}-\mathrm{H}_{3} \mathrm{BO}_{3}$ combination and then solvent removal. This approach uses a reusable $\mathrm{A}_{2}{ }_{2} \mathrm{O}_{3}-\mathrm{H}_{3} \mathrm{BO}_{3}$ combination. The reaction is illustrated in (Scheme 5).

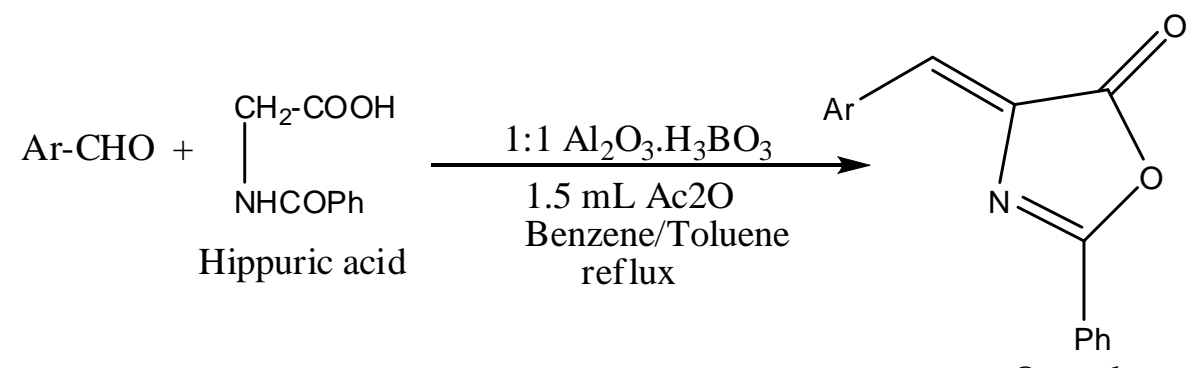

Scheme 5. Synthesis of oxazolone by using neutral alumina and boric acid.

A new synthetic methodology of 4-arylidene-2-phenyl oxazole- 5(4H)-ones using microwaves has also been reported [71]. In this method, hippuric acid and aryl aldehyde using in the equimolar ratio in acetic anhydride were irradiated under microwaves at $2450 \mathrm{M} \mathrm{Hz}$ for 4-5 minutes oxazolones (70-75\% yield) without any catalyst (Scheme 6).

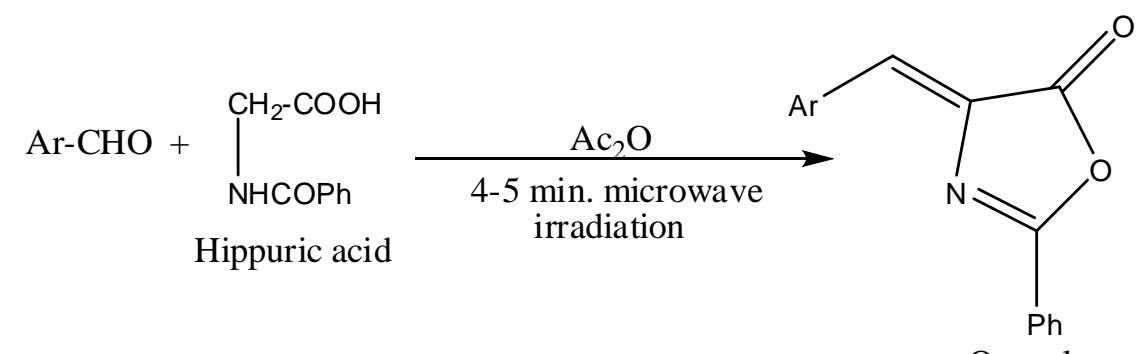

Oxazolone

Scheme 6. Synthesis of 4-arylidene-2-phenyl oxazole- 5(4H)-ones by using acetic anhydride. 
Under microwave irradiation and heat conditions, a solvent-free approach is employed to synthesize 2-phenyl-5(4H)-oxazolones from suitable aldehydes or ketones using hippuric acid in the presence of palladium (11) acetate [72] (Scheme7).<smiles>[R]C(=O)OC1(C(=O)O)N=C(Pc2ccccc2)OC1=O</smiles>

Scheme 7. Solvent-free method for synthesis of 2-phenyl-5(4H)-oxazolones.

The hippuric acid and aryl aldehydes were successfully affected in the cyclodehydration-condensation reaction by utilizing a combination of anhydrous zinc chloride and acetic anhydride for the manufacture of 4-arylidene-2-phenyl oxazol-5(4H) - ones [73]. With a $62-76 \%$ yield yield, this is a fairly easy synthetic method that takes less time (Scheme

$$
\mathrm{Ar}-\mathrm{CHO}+\left.\right|_{\mathrm{NHCOPh}} ^{\mathrm{CH}_{2}-\mathrm{COOH}} \underset{100^{0} \mathrm{C}}{\stackrel{\mathrm{Ac}_{2} \mathrm{O}}{\longrightarrow}}
$$

Hippuric acid

8).

Scheme 8. Synthesis of 4-arylidene-2-phenyl oxazol-5(4H) - ones by using anhydrous zinc chloride and acetic anhydride.

A low yield of lambdoid oxazol-5(4H)-one was obtained by condensing 16formyllambertianic acid methyl ester with hippuric acid in the presence of acetic anhydride and potassium carbonate (Scheme 9) [74].

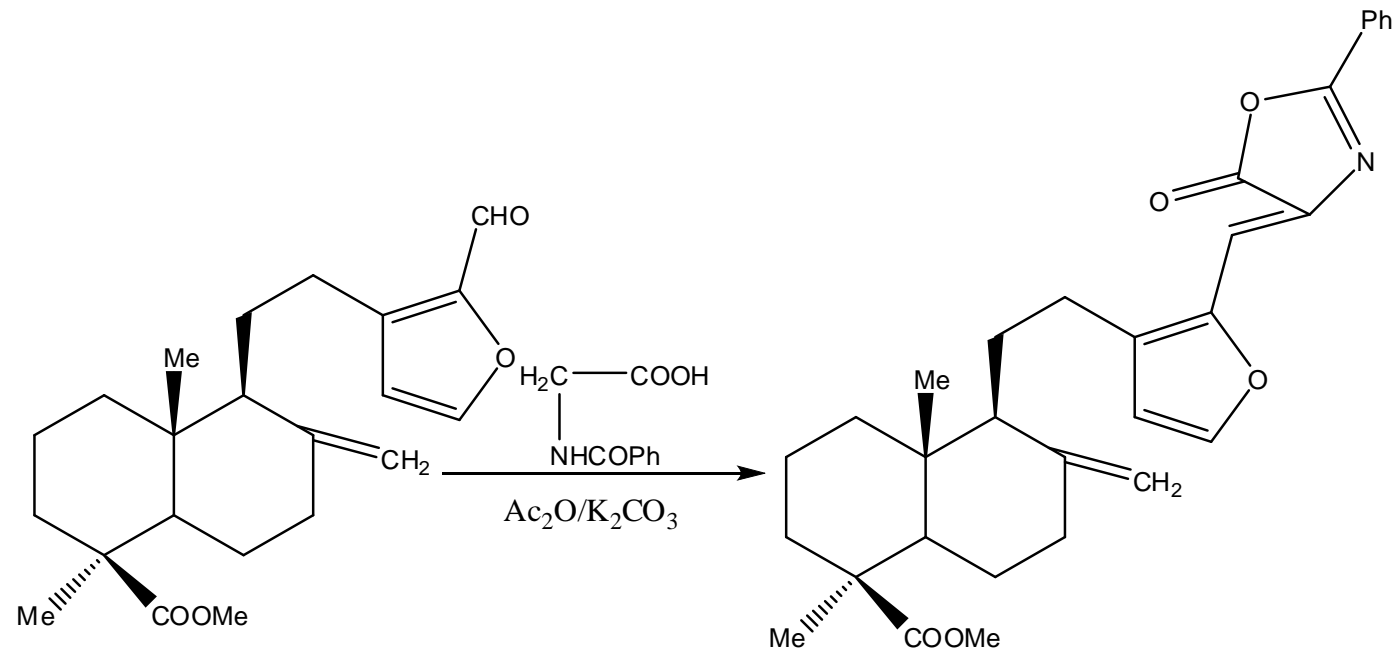

Scheme 9. Synthesis of lambdoid oxazol-5(4H)-one in the presence of acetic anhydride and potassium carbonate.

1-Naphthoyl-glycine reacted with acetic anhydride, and triethyl orthoformate in ethyl acetate under reflux afforded 4-ethoxymethylene-2-[1]-naphthyl-5(4H) -oxazolone (Scheme 10) $[75]$. 

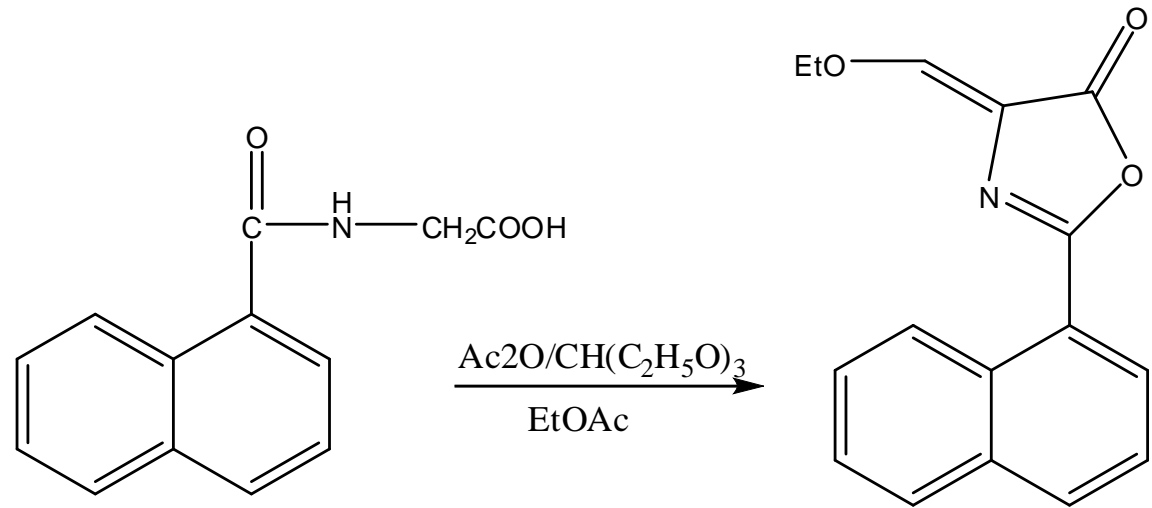

Scheme 10. Synthesis of 4-ethoxymethylene-2-[1]-naphthyl-5(4H)-oxazolone with acetic anhydride, and triethyl orthoformate in ethyl acetate.

When $\alpha$-acylamino acid is treated with phosphorous tribromide in dioxane at room temperature, it produces oxazolone hydrobromide, treated with $\mathrm{CH}_{2} \mathrm{~N}_{2}$, dry $\operatorname{Ag}_{2} \mathrm{O}$, or occasionally aqueous sodium acetate to yield the oxazolone (Scheme 11) [76].

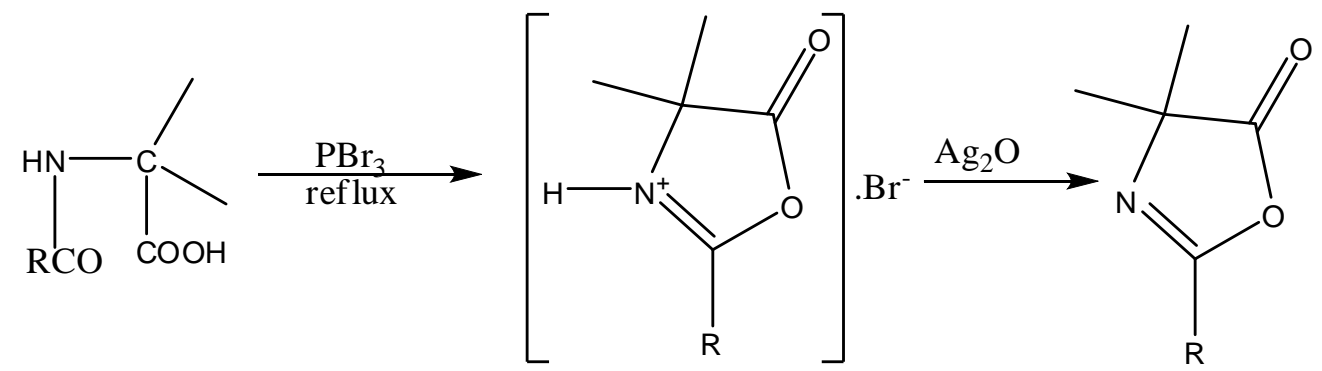

Scheme 11. Synthesis of oxazolone with phosphorous tribromide and silver oxide.

A low yield of 2-styryl-4-( $\alpha$-hydroxy ethylidene)-2-oxazolin-5-one was obtained by condensing cinnamoyl glycine with acetic anhydride and sodium acetate. (Scheme 12) [77].

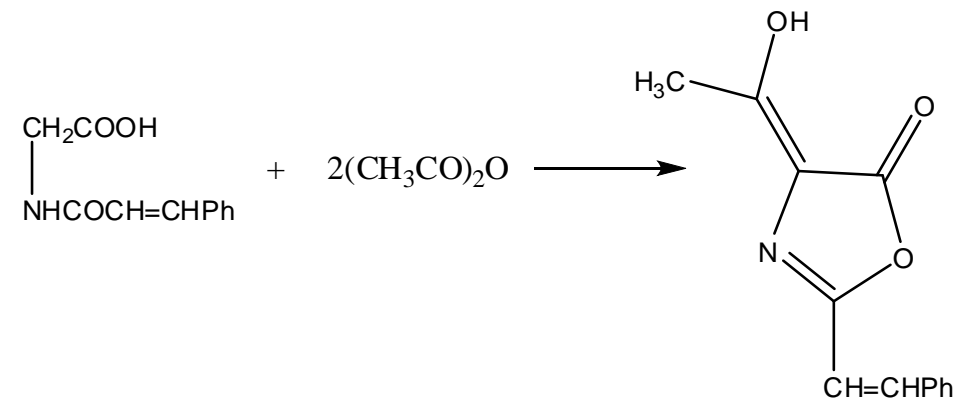

Scheme 12. Synthesis of 2-styryl-4-( $\alpha$-hydroxy ethylidene)-2-oxazolin-5-one by using acetic anhydride and sodium acetate.

Treatment of 2, 3-dihydro-1,3-diphenyl-1H-pyrazole-4-carbaldehyde with hippuric acid afforded the corresponding (1,3-diphenyl-4-pyrazolin)-4-methylene-2-oxazolin-5-one (Scheme 13) [78].

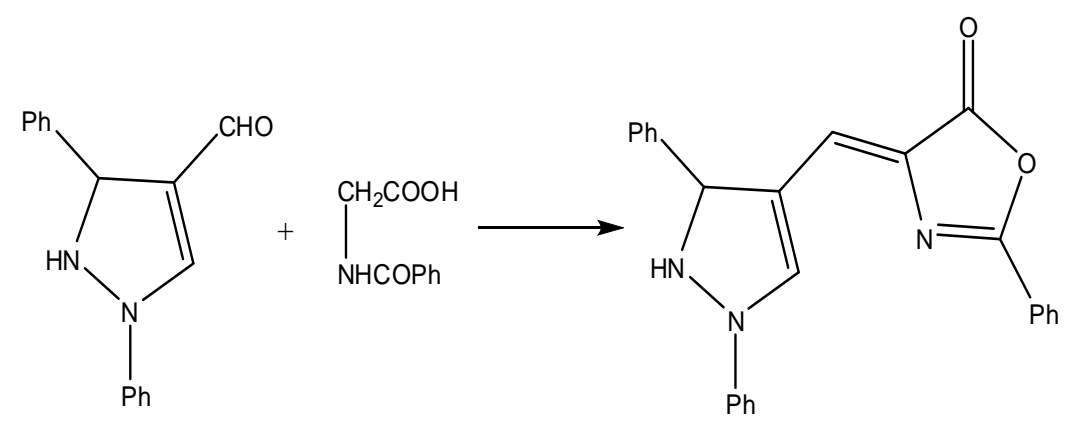

Scheme 13. Synthesis of (1,3-diphenyl-4-pyrazolin)-4-methylene-2-oxazolin-5-one. 


\section{The Bergmann Synthesis}

In this synthesis, oxazolones can be prepared by the action of acetic anhydride on certain $\alpha$-- $\alpha$-haloacyl--amino acids [79].

Bergmann and Stem discovered that acetic anhydride and pyridine react with $\mathrm{N}$ chloroacetyl phenylalanines to produce 2-methyl-4-benzylidene-5(4)-oxazolone. Other -("haloacetyl)-amino acids exhibited comparable behavior. (Scheme 14).

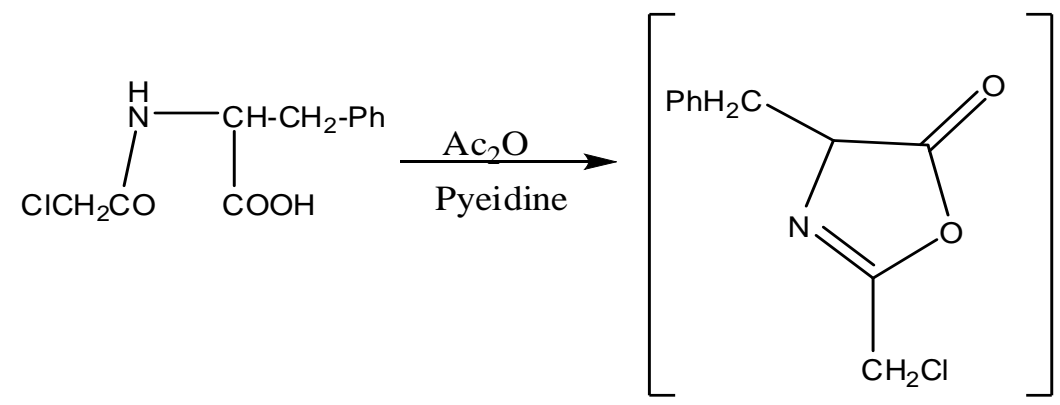

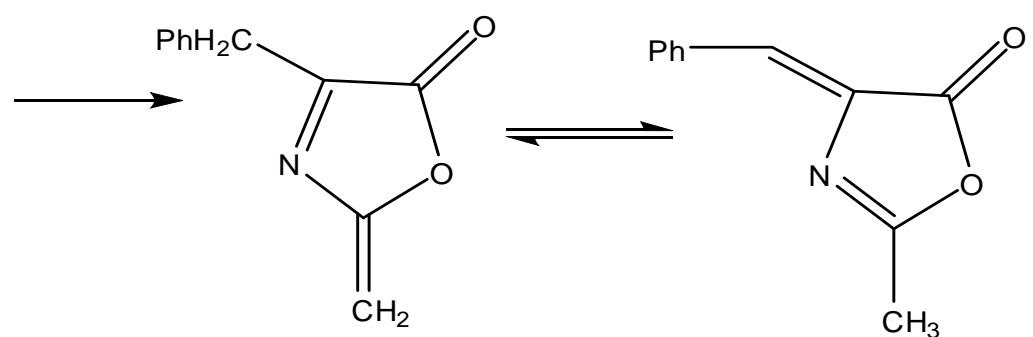

Scheme 14. Synthesis of 2-methyl-4-benzylidene-5(4)-oxazolone by acetic anhydride and pyridine.

\section{DCC Method}

Di cyclo hexyl carbodiimide (DCC) in chloroform and other solvents can similarly alter acylamino acid dehydration (Scheme 15). The DCC approach has been used to make several optically active azlactones.<smiles>[R]C(=O)NCC(=O)O</smiles><smiles>CCCCC</smiles><smiles>[R]C1=NCC(=O)O1</smiles>

$+\mathrm{C}_{6} \mathrm{H} 11 \mathrm{NHCONHC} \mathrm{H}_{11}$

Scheme 15. Synthesis of azalactone by the DCC method.

\section{Miscellaneous Methods}

The equivalent 4-benzylidene-2-methyl-2-oxazolin-5-one (Scheme 16) was obtained by reacting 4-acetamido-5-phenyl-3-isothiazolidinone-1, 1-dioxide with an acetic anhydridepyridine combination [80].
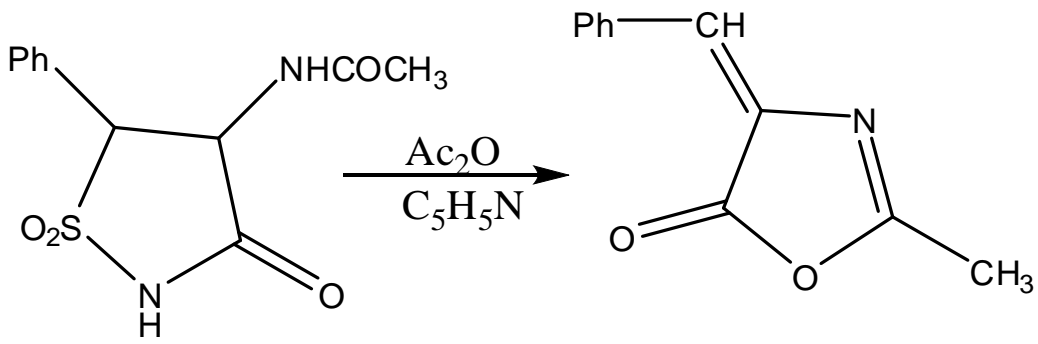

Scheme 16. Synthesis of 4-benzylidene-2-methyl-2-oxazolin-5-one with acetic anhydride-pyridine mixture. 
The acid catalyzed rearrangement of 3-benzamido-1, 4-diphenyl-2-azetidinone gave 4benzylidene-2-phenyl-2-oxazolin-5-one (Scheme 17) [81].

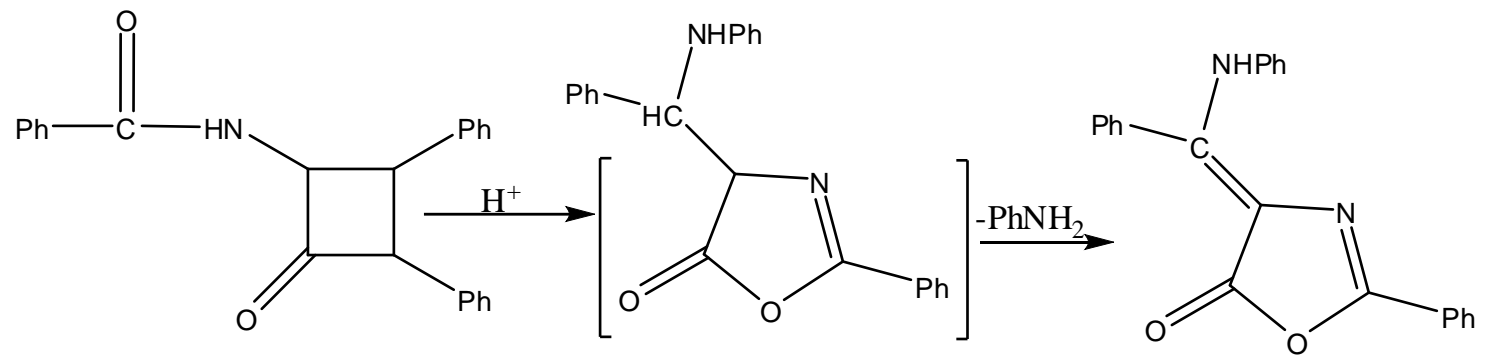

Scheme 17. Acid catalyzed synthesis of 4-benzylidene-2-phenyl-2-oxazolin-5-one.

Coupling aroylglycines with the appropriate aryldiazonium salts in acetic anhydride containing freshly fused sodium acetate at $0{ }^{\circ} \mathrm{C}$ gave 2-aryl-4-aryl azo-2-oxazoline-5-ones (Scheme 18)[82-84].

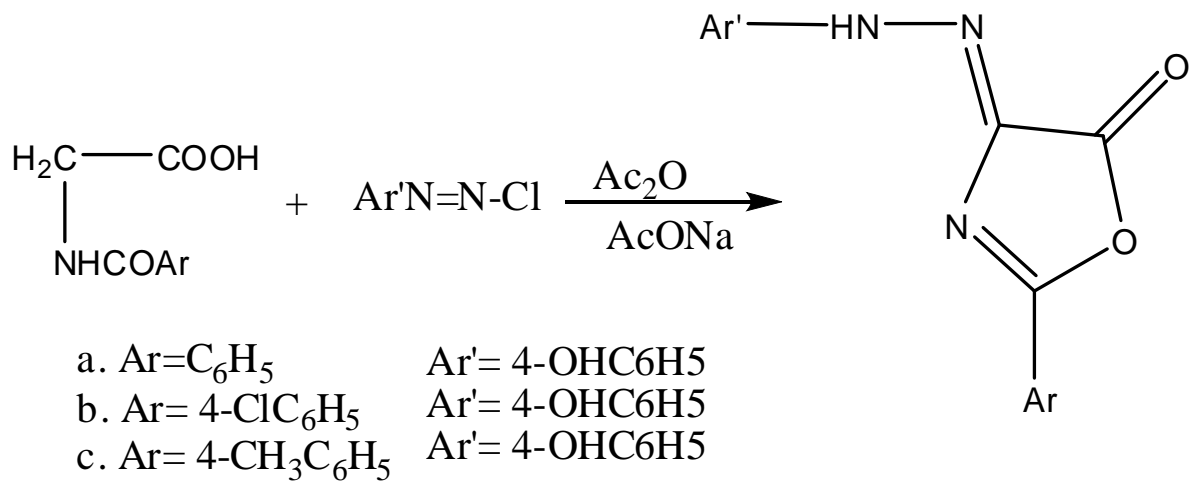

Scheme 18. Synthesis of 2-aryl-4-aryl azo-2-oxazoline-5-ones in acetic anhydride containing freshly fused sodium acetate.

Tetrafluoropropiomc anhydride converts amino acids directly to saturated azlactones containing the tetrafluoroethyl group (Scheme 19) [85].<smiles>[R]C(N)C(=O)O</smiles><smiles>CCCOC(=O)C(NC(=O)OCC)C(=O)OCC(F)F</smiles>

$\mathrm{R}=\mathrm{CH} 3, \mathrm{C} 2 \mathrm{H} 5, \mathrm{n}-\mathrm{C} 3 \mathrm{H} 7, \mathrm{n}-\mathrm{C} 4 \mathrm{H} 9$ and $\mathrm{C} 6 \mathrm{H} 5 \mathrm{CH} 2$

Scheme 19. Synthesis of saturated azlactones containing the tetrafluoroethyl group.

DL - amino acids reportedly react with N-phenyl benzimido chloride in benzene containing triethylamine to give saturated azlactones (Scheme 20) [86].<smiles>CCCCCCC(N)C(=O)OCC(C)C1(C)N=C(Cc2ccccc2)OC1=O</smiles>

Scheme 20. Synthesis of saturated azlactones by DL - amino acids.

Acid-catalyzed cyclization of diamides, which may be reported as activated $\mathrm{N}$-acyl-aamino acids, also leads to the formation of saturated azlactones (Scheme 21) [87]. 


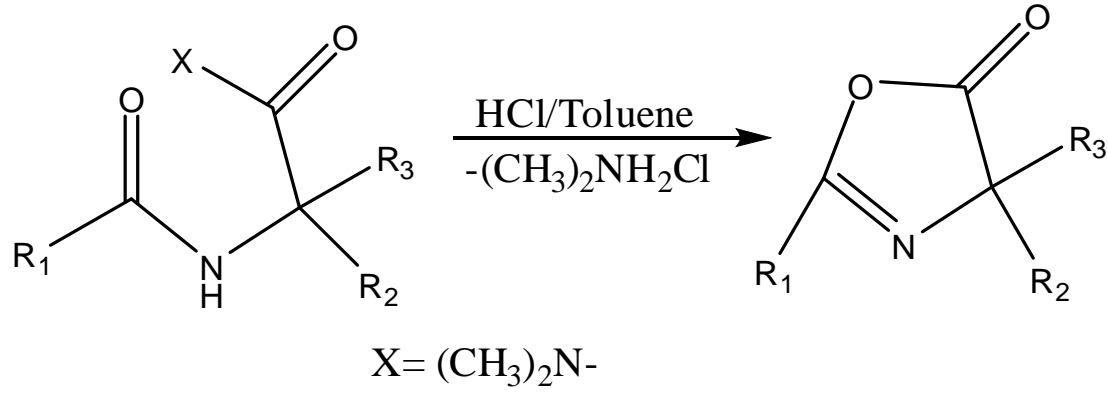

Scheme 21. Synthesis of saturated azlactones by acid-catalyzed cyclization of diamides.

Saturated azlactones have also been obtained from acetamidomalonic acid ester by alkylation, hydrolysis, and cyclization with acetic anhydride (Scheme 22) [88].

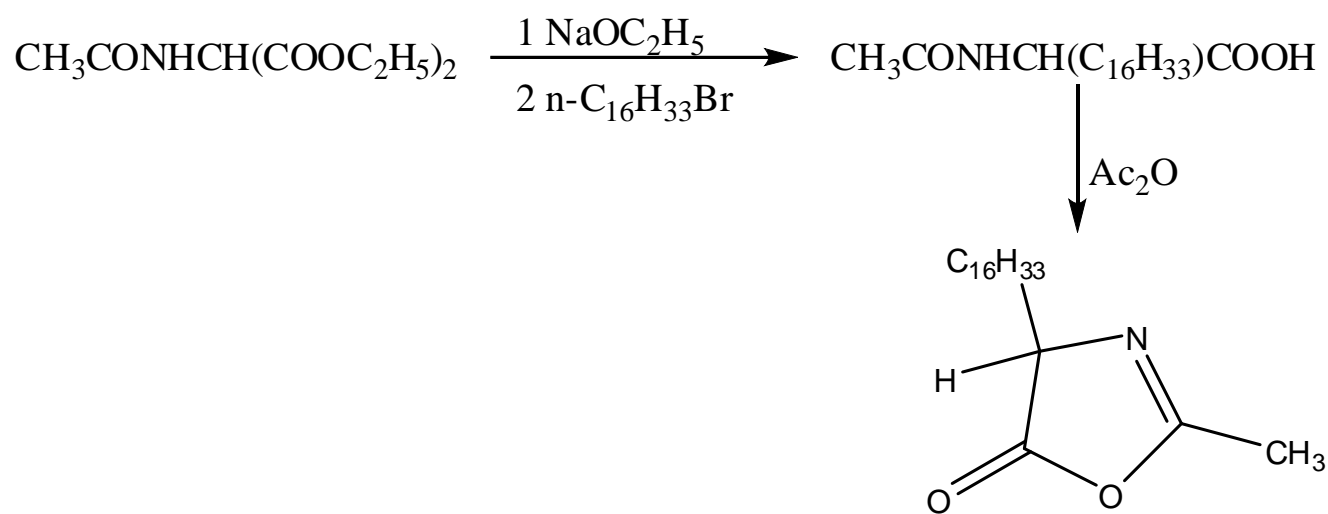

Scheme 22. Synthesis of saturated azlactones from acetamidomalonic acid ester.

\section{Chemical Reactivity of Oxazolone}

Azlactone is a useful intermediate for the synthesis of a variety of different types of a compound, including $\alpha$-amino and $\alpha$-keto acids.

\section{Hydrolysis of the Azlactone}

Hydrolysis of the azlactone yields $\alpha$-acylaminoacrylic acids, which on reduction give $\alpha$-amino acids (Scheme 23). Phenyl amine has been prepared by this method in $86 \%$ yields [89].

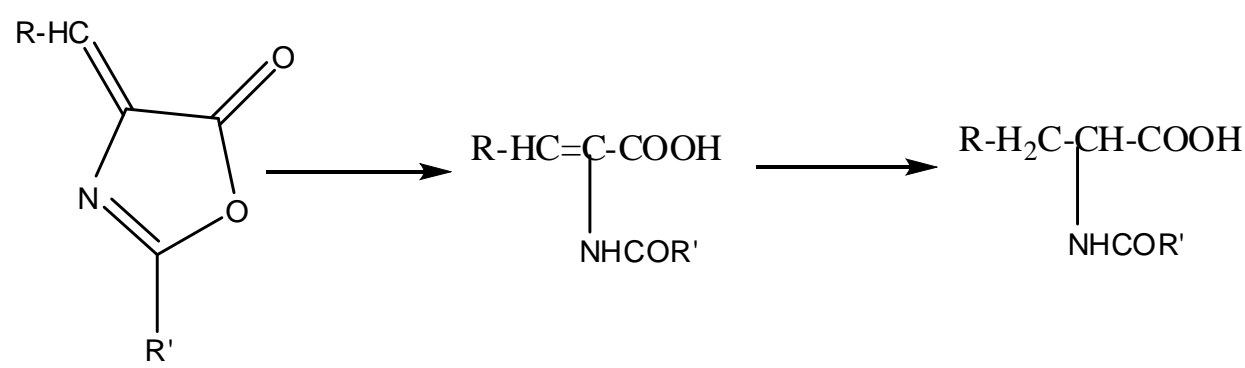

Scheme 23. Hydrolysis of the azlactone yields $\alpha$-acylaminoacrylic acids.

Treatment of the azlactone with amines and amino acids produces amides and dipeptide derivatives. The 2-oxazolin-5-one derivatives react readily with primary amines than with secondary amines via ring-opening of oxazolone at $\mathrm{C} 5$ to give the corresponding amides (Scheme 24) [90]. 

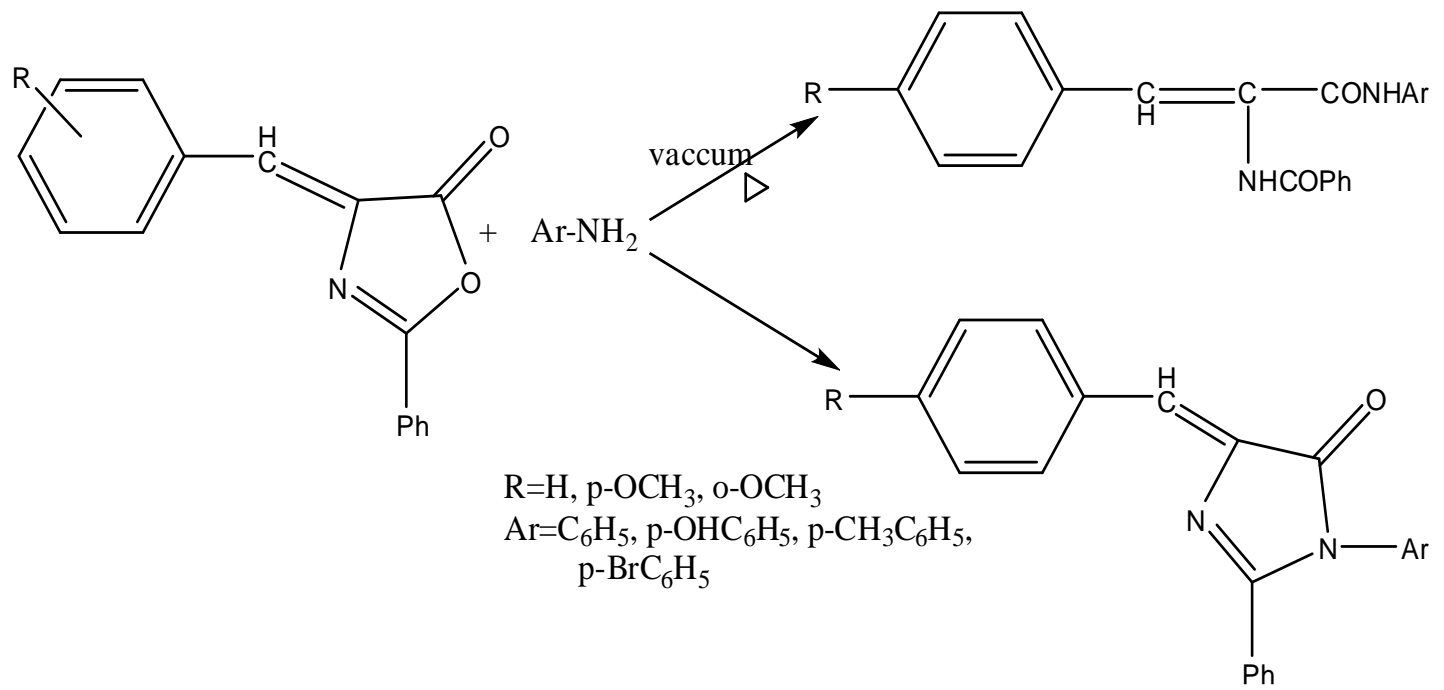

Scheme 24. Hydrolysis of the azlactone with amine and amino acid to produce amides and dipeptide derivatives.

\section{Thermal and Photochemical Reactions}

Simple 5(4H)-oxazolones are stable at moderate temperatures. The diphenyl derivative yields the acylamine on flash vacuum pyrolysis. The presence of aryl substituents at C-4 destabilizes the ring;such compounds rearrange at $180^{\circ}$ to oxazoles (Scheme 25) [91].

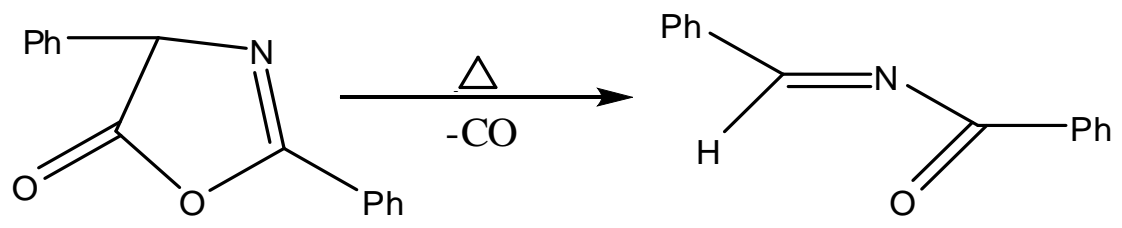

Scheme 25. Flash vacuum diphenyl pyrolysis of 5(4H)-oxazolones to yield acylamine.

\section{Alkylation Reactions}

Saturated azlactones have been alkylated in aprotic solvents such as anhydrous dimethylformamide, to yield 4, 4 - disubstituted azlactones (Scheme 26) [92].

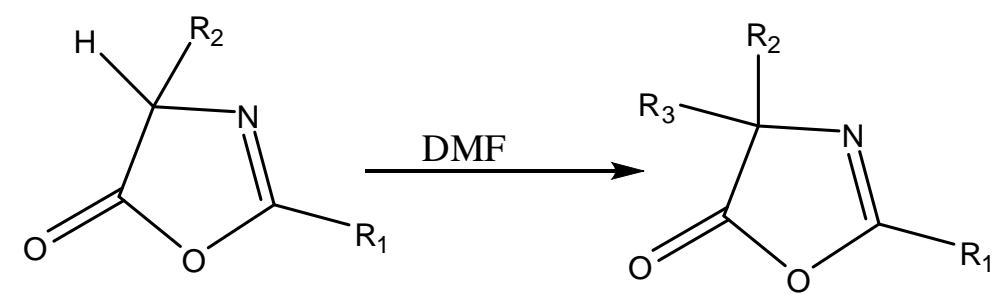

Scheme 26. Alkylation Reactions of Saturated azlactones in aprotic solvents.

\section{Dakin-West Reactions}

Three stages make up the Dakin-West reaction for converting -amino acids to aacylamino ketones (Scheme 27): (a) acylation of the amino acid followed by cyclodehydration to produce 2-oxazol-5-ones, (b) acylation of the oxazolone to produce its 4-acyl analog, and (c) oxazolone ring opening followed by decarboxylation to produce 2-oxazol-5-ones. Despite the fact that this approach can be used to make 4-acyl azlactones [93]. 


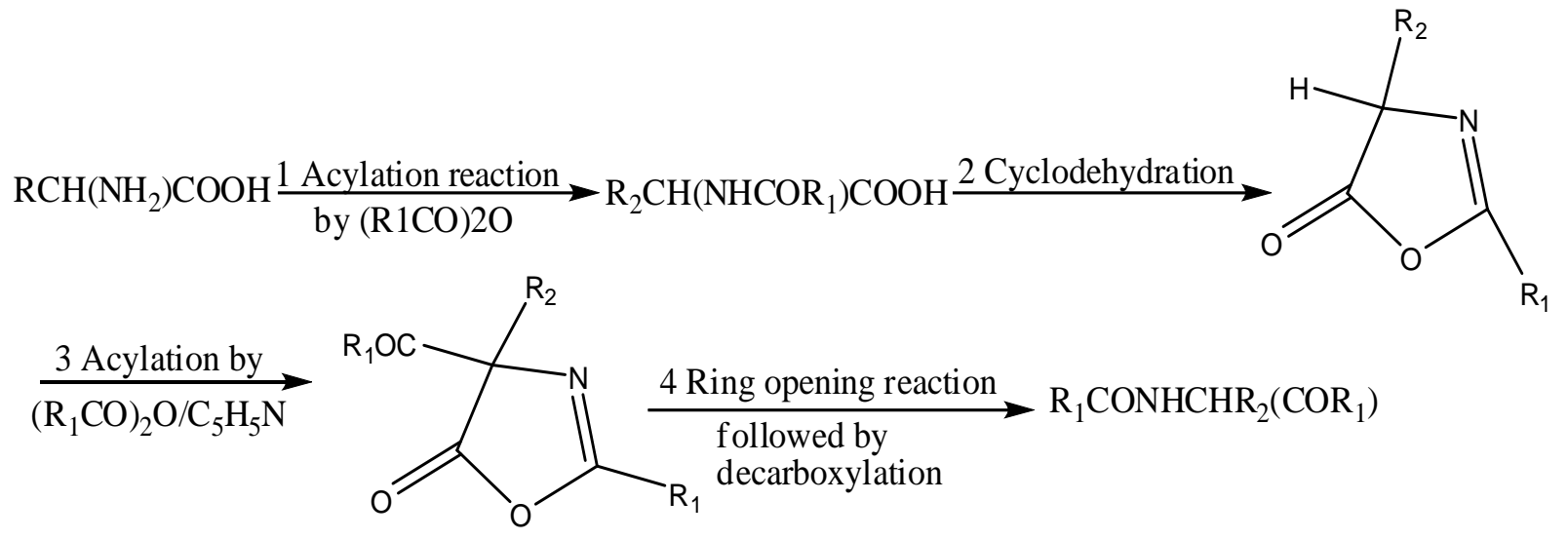

Scheme 27. Convertion of $\alpha$-amino acids to $\alpha$ - acylamino ketones by Dakin - West reaction.

\section{Hydrazinolysis}

The reaction of 4-benzylidene-2-styryl-5(4)-oxazolone with p-nitro phenylhydrazine to produce hydrazide was reported (Scheme 28) [94-98].

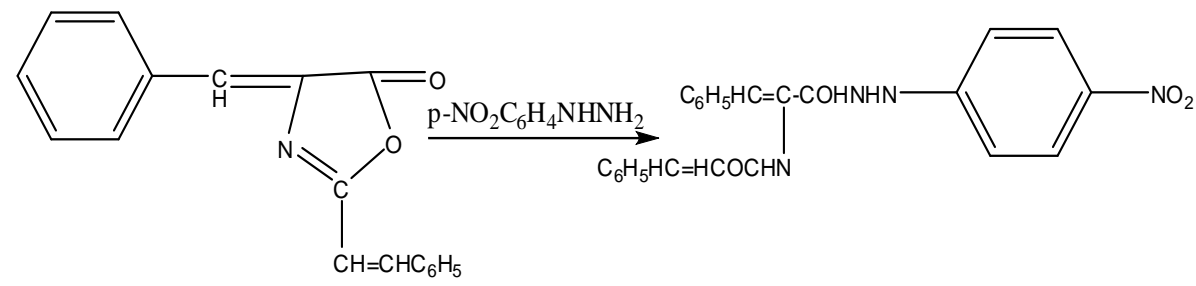

Scheme 28. Hydrazinolysis of 4- benzylidene-2-styryl-5(4)-oxazolone.

At ambient temperature, hydrazinolysis of oxazolone with hydrazine yielded cyclic hydrazides (Scheme 29) [99].<smiles>[R]C1=NC(=C2C(=O)N(C(C)C)c3ccccc32)C(=O)C1=C1CC(P)[NH+](N)C1=O</smiles>

Scheme 29. Preparation of cyclic hydrazides by hydrazinolysis of oxazolone.

\section{Aminolysis}

Except for some 4-hetero methylene oxazolones, oxazolones react with amines at C-5. Most 5(4)-oxazolones reacted more easily with primary amines than secondary amines [100$102]$.

The aminolysis of 4-arylidene-2-(2'-furyl)-5(4) - oxazolone with aromatic amines in benzene yielded -(2-furamido)-N-substituted cinnamides, according to the study (Scheme 30).

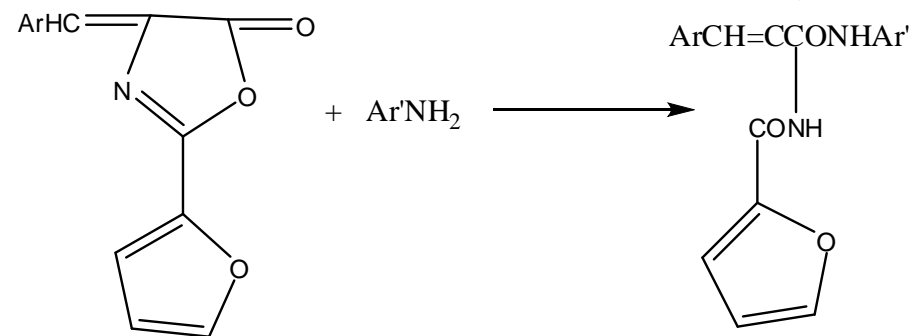

Scheme 30. Aminolysis of 4-arylidene-2-(2'-furyl)-5(4) - oxazolone. 
Kandile et al.[103], found that the aminolysis of oxazolone with $\mathrm{H}_{2} \mathrm{NR},(\mathrm{R}=\mathrm{NHPh}$, $\mathrm{CH} 2-\mathrm{Ph}, \mathrm{Ph}$ ) gave amides (Scheme 31).

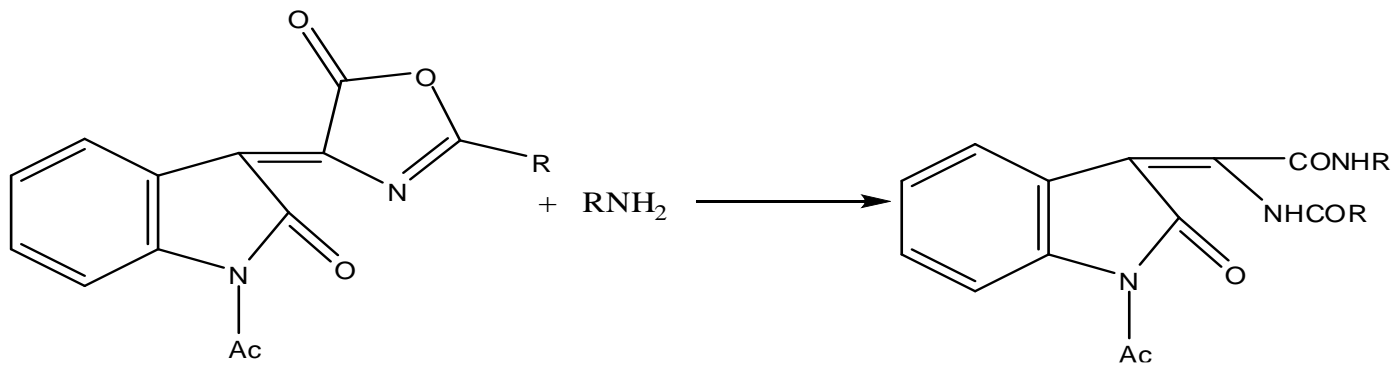

Scheme 31. Preparation of amides by aminolysis of oxazolone.

\section{Action with Amino Acids}

The use of oxazolones for the synthesis of peptides was originated by Mohr and others [104] to give compounds have antibiotics that have antitumor properties.

In the reaction with - amino acid, the oxazolone (which can be saturated or unsaturated at C-4) acts as an acid anhydride. The most frequent medium is aqueous acetone, with sodium hydroxide added to neutralize the acid released (Scheme 32)[105-109].<smiles>[R]C1=NC(C)(C)C(=O)O1</smiles><smiles>[R]C(N)C(=O)NC(C)C([R])NC(=O)O</smiles>

Scheme 32. Acid anhydride action of oxazolone with amino acid.

\section{Thiolysis}

When oxyazolones were combined with a thiol, the thioester was formed. The reaction of 2-phenyl-5(4)-oxazolone with benzyl-mercaptan yielded benzyl thiohippurate, according to [110] (Scheme 33).

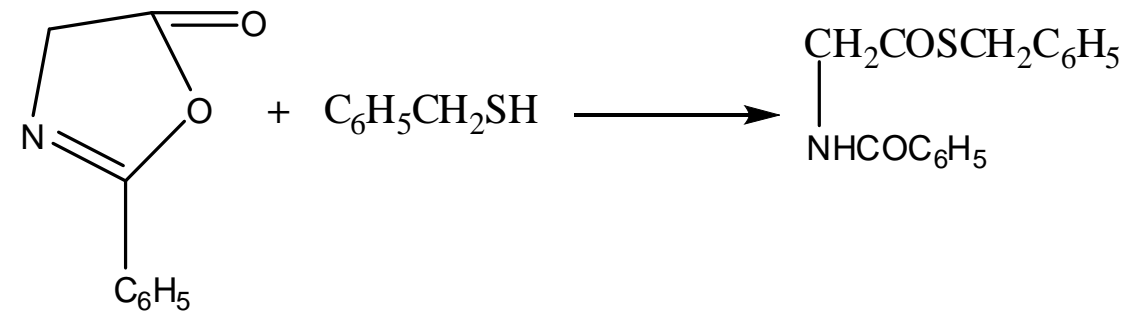

Scheme 33. Thiolysis reaction of oxazolones with a thiol.

\section{The Action of Hydroxylamine Hydrochloride}

Oxazolone reacts with hydroxylamine hydrochloride by carbonyl oxygen fission, which is followed by cyclization [111].

4-arylidene-2-(2'-furyl)-5(4)-oxazolones were converted to 4-arylidene-2-(2'-furyl)-5imidazolones by treating them with hydroxylamine hydrochloride (Scheme 34). 


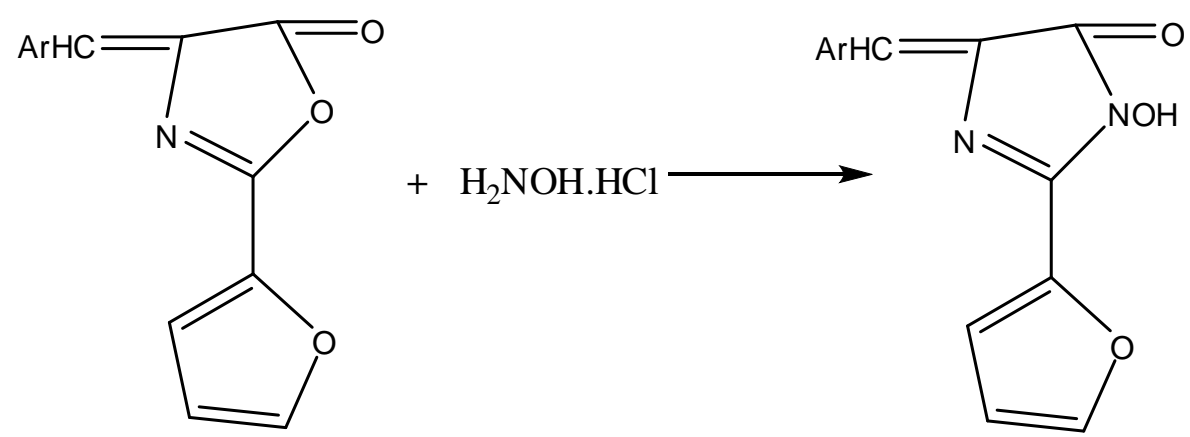

Scheme 34. The reaction of oxazolone with hydroxylamine hydrochloride.

\section{Hydrolysis and Alcoholysis}

Unless they contain some unsaturated stabilizing stabilizing group, oxazolones are hydrolyzed to a-acylamino acid even in cold water or moist air [112].

The most effective single substituent is a 4-arylidene group. Thus, 2-methyl-4benzylidene-5(4)-oxazolone is very stable in cold water, while boiling with aqueous acetone hydrolyzes it to -acetamidocinnamic acid (Scheme 35).

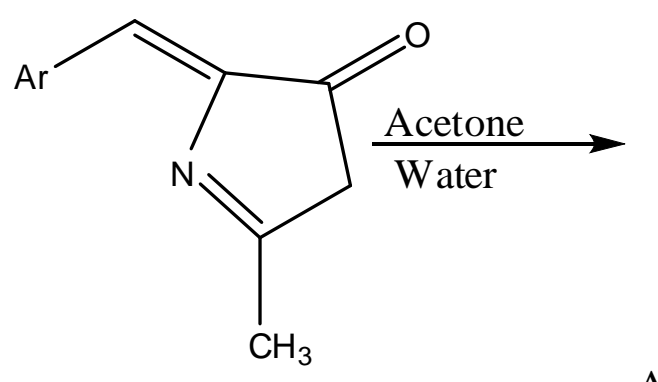
Ar= Phenyl or substituted phenyl group<smiles>CC(=O)NC(=O)O</smiles>

Acetamido Cinnamic acid derivative

Scheme 35. Hydrolysis of oxazolone to yield $\alpha$-acylamino acid.

Water nucleophilically attacks the $\mathrm{C}=\mathrm{N}$ group of 2-alkenyl-5(4H)-oxazolones to generate a reversible intermediate, which is then ketonized to form $\alpha$-acylamino acid (Scheme 36) $[113-115]$.
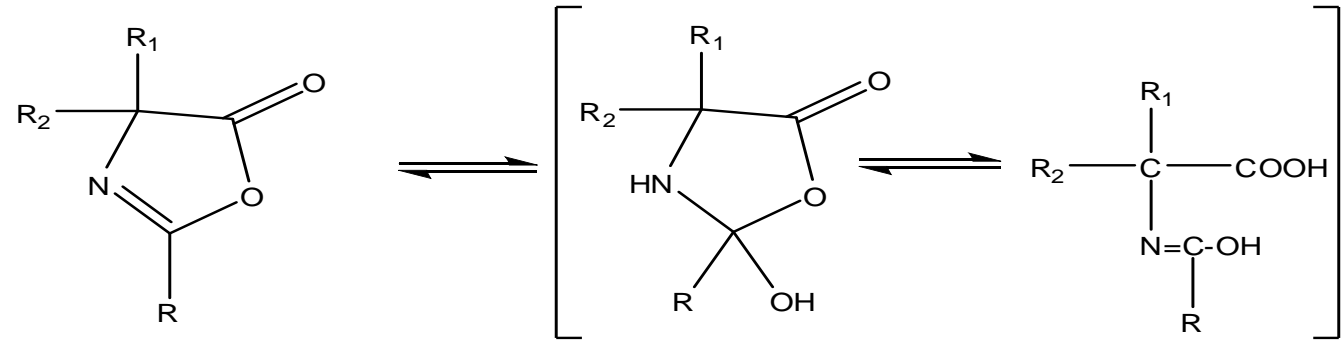

Scheme 36. Ketonization of 2-alkenyl-5(4H)-oxazolones to form $\alpha$-acylamino acid. 


\section{Friedel-Crafts Reaction}

According to Filler et al., 2-phenyl-4-benzylidene-5(4)-oxazolone interacted with benzene, toluene, m-xylene, or chlorobenzene via the action of anhydrous aluminum chloride to provide the,-diphenylalanine (Scheme 37) [116-117].<smiles>O=C1OC(c2ccccc2)=N/C1=C\c1ccccc1</smiles><smiles>CC(C(=O)O)[C@H](C)C(=O)O</smiles>

$\underset{6 \mathrm{~N} \mathrm{HBr}, \text { Heat }}{\longrightarrow}$

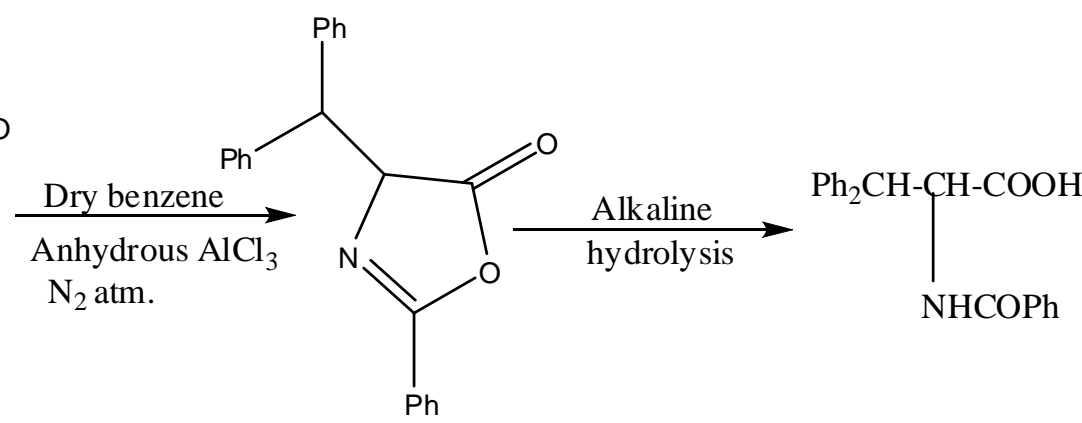

$\mathrm{NH} 2$

Diphenylalanine

Scheme 37. Friedel-Crafts Reaction2-phenyl-4-benzylidene-5(4)-oxazolone to yield $\beta$, $\beta$-diphenylalanine.

\section{Action of Grignard Reagents}

It was reported [118-119] that 2-phenyl-4-methyl-5(4)-oxazolone reacted with excess phenyl magnesium bromide to give 1, 1-diphenyl-2-benzamido-1- propanol (Scheme 38).

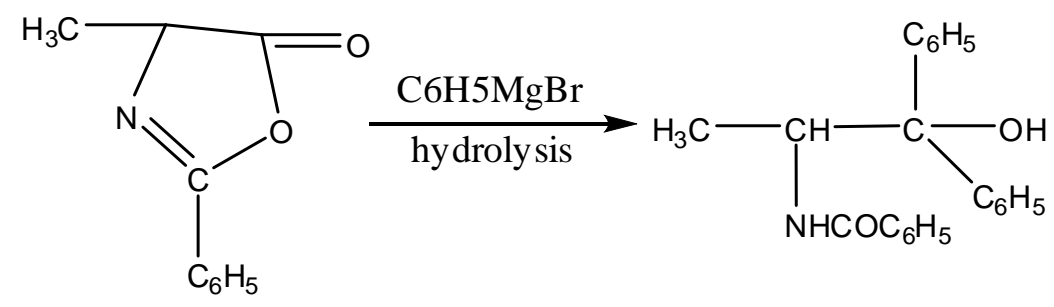

Scheme 38. Grignard Reaction of 2-phenyl-4-methyl-5(4)-oxazolone to produce1, 1-diphenyl-2-benzamido-1propanol.

\section{Application of Oxazolone Nucleus}

22.1. Conversion to other heterocyclic compounds.

22.1.1. Thiazolones.

Unsaturated azlactones react with thioacetic acid at $100^{\circ}$ for $18 \mathrm{hr}$ in the presence of triethylamine to give unsaturated thiazolones (Scheme 39) [120-121].

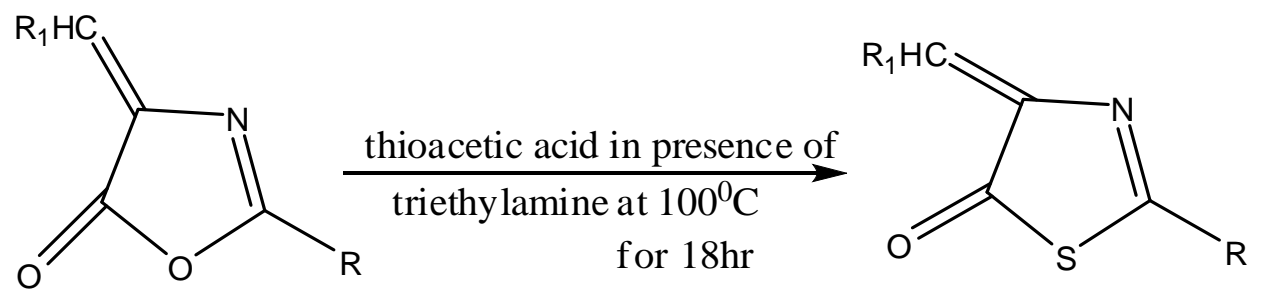

Scheme 39. Conversion of unsaturated azlactones to unsaturated thiazolones. 


\subsubsection{Pyrazolones.}

The reaction of unsaturated azlactones with hydrazine hydrates substituted hydrazines, or amines have been extensively studied [122].

Two isomeric products are obtained in the reaction with hydrazine; depending on the reaction temperature, normal hydrazide is obtained at room temperature on reaction with 99 $9 \%$ hydrazine hydrate and the hydrazine adduct on reaction with $50 \%$ hydrazine in ethanol. The conversion may be affected by heating (Scheme 40).
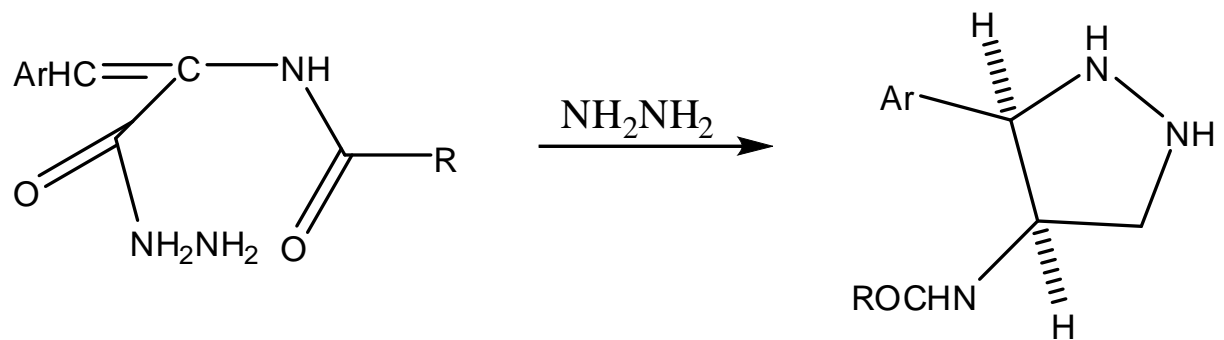

Scheme 40. Conversion of unsaturated azlactones to pyrazolones.

\subsubsection{Tetrazoles.}

Oxazolones react with a sodium azide anhydrous aluminum chloride mixture in tetrahydrofuran to give tetrazolyl acrylic acids (Scheme 41) [123].

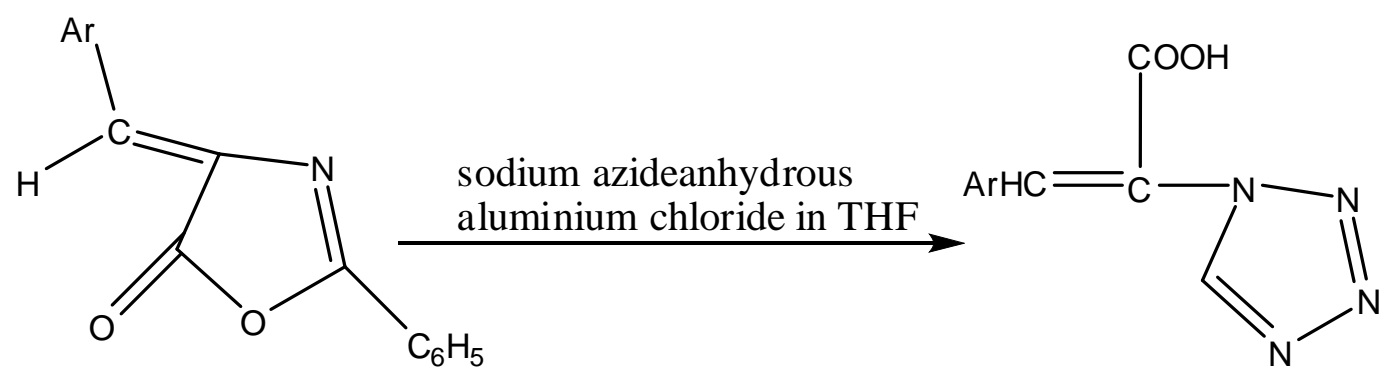

Scheme 41. Conversion of unsaturated azlactones to tetrazolyl acrylic acids.

The reaction can also be carried out by heating glacial acetic acid with a sodium azide solution in water. The tetrazolyl acrylic acids readily undergo decarboxylation to give 1, 5disubstituted tetrazoles (Scheme 42).

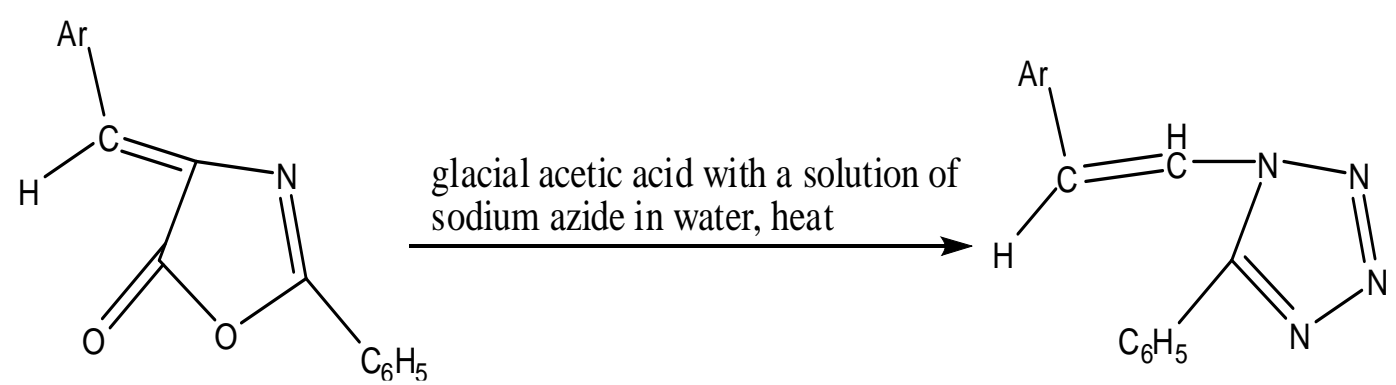

Scheme 42. Conversion of unsaturated azlactones to 1, 5-disubstituted tetrazoles.

22.1.4. Imidazolones.

Azlactones react with alcoholic ammonia in the presence of potassium carbonate to give lmidazolones (Scheme 43) [124]. 

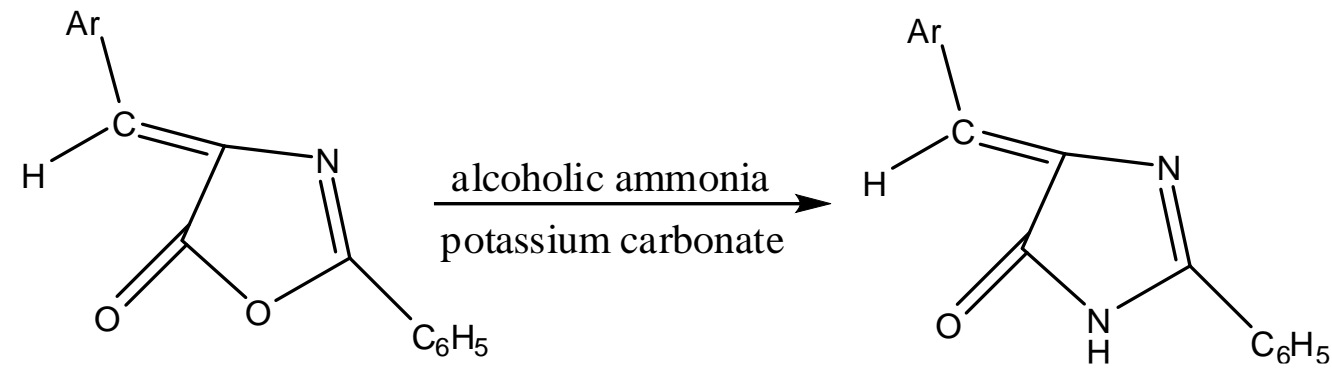

Scheme 43. Conversion of unsaturated azlactones to lmidazolones.

22.1.5. Isoxazolidones.

Alkylidene azlactones react with methanolic solutions of hydroxylamine acetate to yield substituted isoxazolidones (Scheme 44) [125].<smiles>CC(C)=C1N=C(c2ccccc2)OC1=O</smiles>

methanolic solution of $\stackrel{\text { hydroxyl amine acetate }}{\longrightarrow}$<smiles>CCCN1C(=O)ONC1(C)C</smiles>

Scheme 44. Conversion of alkylidene azlactones to yield Isoxazolidones.

22.1.6. Isoquinoline derivatives.

When 2-phenyl-4-benzylidene-2-oxazolin-5-one is treated with anhydrous aluminum chloride in tetrachloroethane, intramolecular imidoylation occurs with the formation of 1 phenyl-isoquinoline carboxylic acid (Scheme 45).

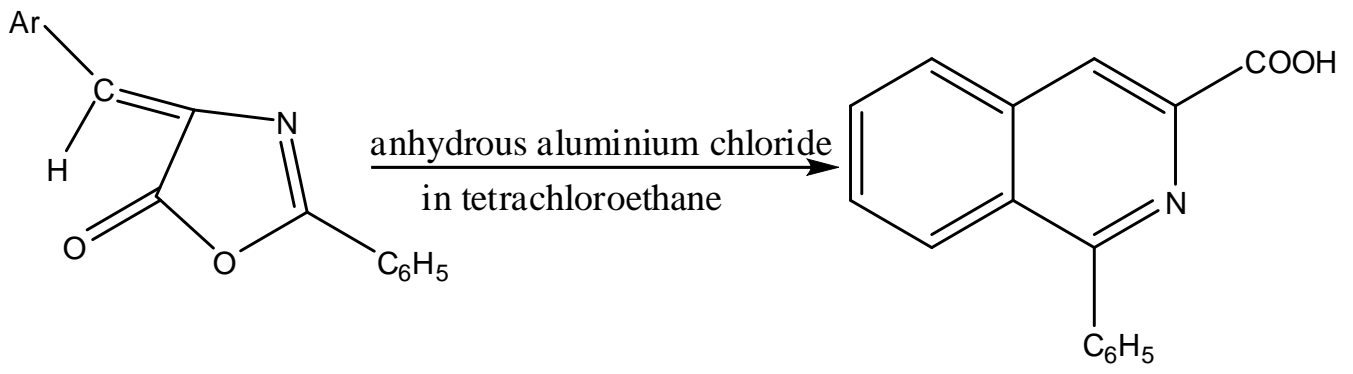

Scheme 45. Conversion of 2-phenyl-4-benzylidene-2-oxazolin-5-one to 1 - phenyl-isoquinoline carboxylic acid.

In this review, we have discussed chemistry, methods of synthesis, and reactivity of oxazolone nucleus. It shows various pharmacological activities such as antimicrobial, antidiabetic, anticancer, anti-inflammatory, etc., listed in Table 1.

Table 1. Biological activities of oxazolone-containing drugs.

\begin{tabular}{l|l|l} 
SN & Drug name & Uses \\
\hline 1. & Antibiotic has a broad spectrum of action that is used to treat \\
tuberculosis and certain urinary tract infections. (UTI).
\end{tabular}




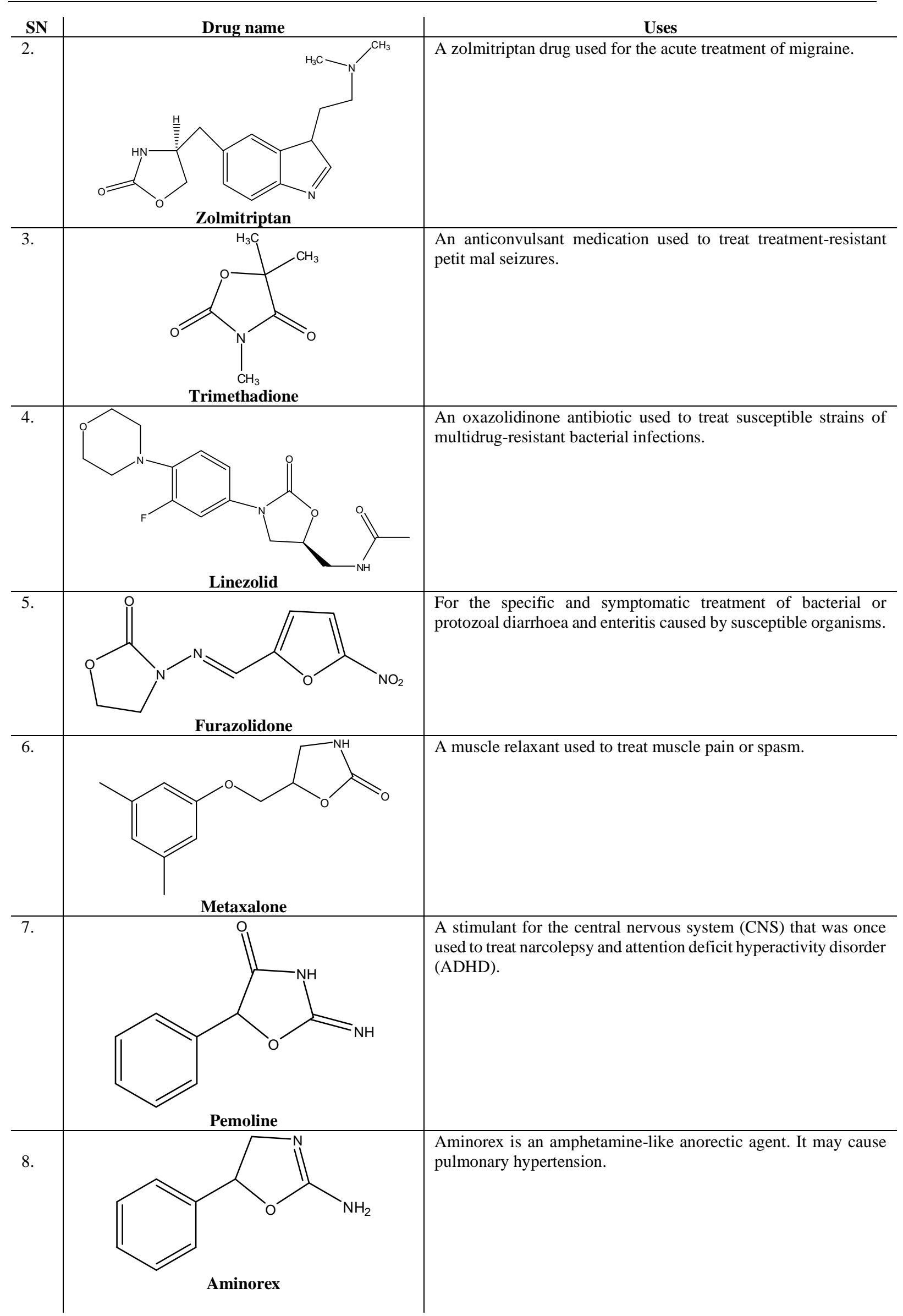




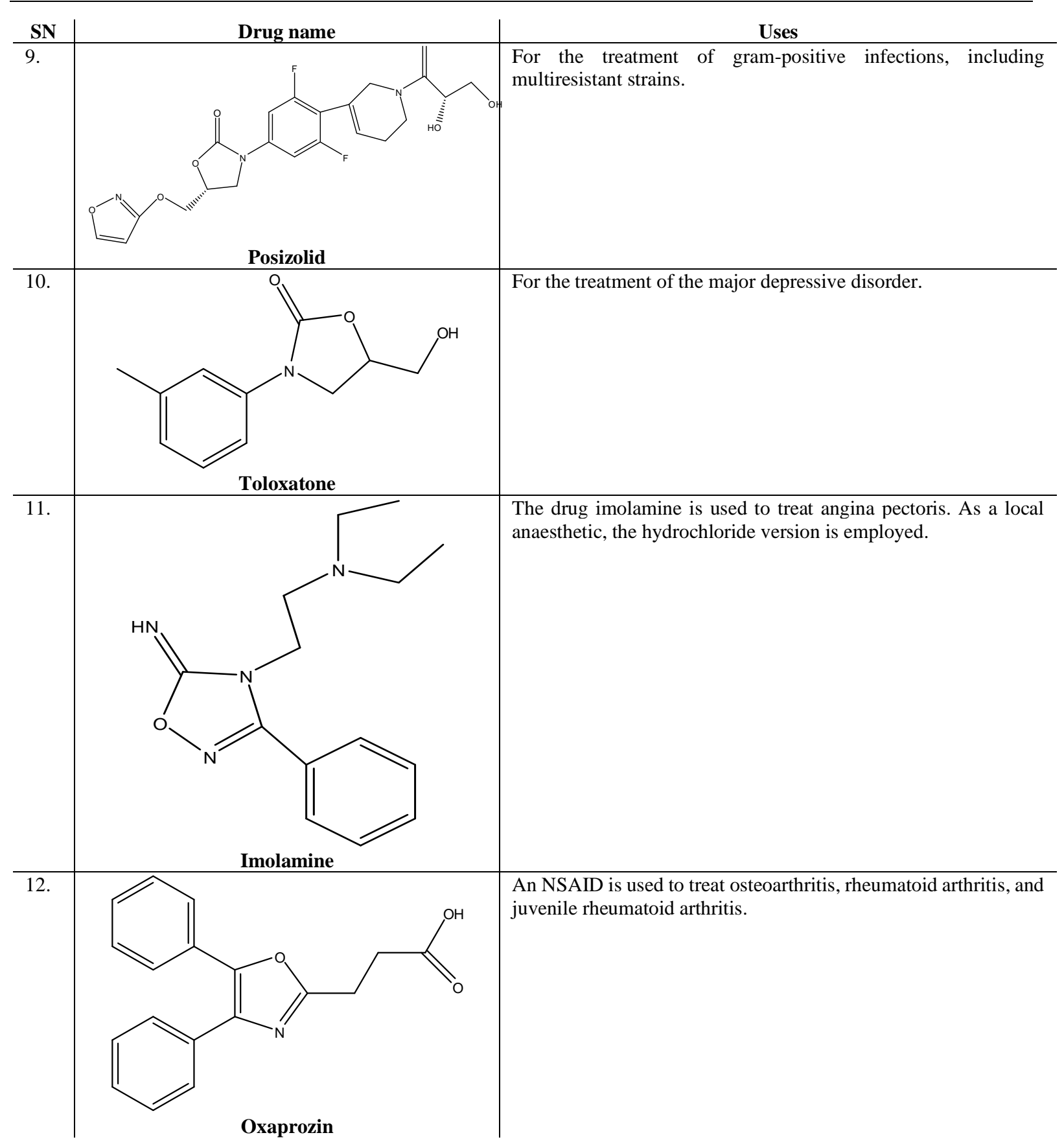

\section{Conclusions}

This review shows that oxazolone is a very interesting, biologically rich nucleus in heterocyclic chemistry. We have given various synthetic routes for the synthesis of oxazolone moiety. It is also used for making small molecular intermediates for the synthesis of the pharmacologically active agent. Oxazolone undergoes various synthetic reactions to prepare heterocyclic compounds, which have been mentioned in this review. A list of pharmacologically active drugs is also reported in this review. Based on this review, it has been proved that oxazolone to be helpful for further research work for the development of potent medicinal agents.

\section{Funding}

None. 


\section{Acknowledgments}

Authors are thankful to the scholars whose articles are cited for this reference article and were very helpful while writing this manuscript.

\section{Conflicts of Interest}

The authors declare no conflicts of interest.

\section{References}

1. Aaglawe, M.J.; Dhule, S.S.; Bahekar, S.S.; Wakte, P.S.; Shinde, D.B. Synthesis and antibacterial activity of some oxazolone derivatives. Journal of Korean Chemical Society2003, 47, 133-136, http://dx.doi.org/10.5012/jkcs.2003.47.2.133.

2. Giovanni, P.; Cinzia, T.; Lara, B.; Alice, B.; Maria, M.C.; Lara, S.; Laura, Q.; Annalisa, D.P.; Leonardo, C.; Antonia, R.; Giovanni, L. Densely Functionalized 2-Methylideneazetidine: Evaluation as Antibacterials. Molecules2021, 26, 3891-3908, https://doi.org/10.3390/molecules26133891.

3. Ismail, M.I. Physical characteristics and polarographic reduction mechanism of some oxazolones. Canadian Journal of Chemistry1991, 69, 1886-1892, https://doi.org/10.1139/v91-273.

4. Park, B.S.; Min, Oh.C.; Chun, K.H.; Lee, J.O. Photoinduced one pot transformation of 2- phenyl-4ethylidene-5(4H)-oxazolone and allylic alcohols to $\gamma, \delta$-unsaturated N-benzoyl amides. Tetrahedron Letters1998, 39, 9711- 9714,https://doi.org/10.1016/S0040-4039(98)02232-1.

5. Palcut, M. Spectral properties of novel 1, 3- oxazol-5(4H)-ones with substituted benzylidene and phenyl rings. Acta Chimica Slovenica2009, 56, 362-368.

6. Lamya, H.A.W.; Ahmed, A.B.M.; Samar, S.T.; Hanan, M.H.; Ali, A.E. 1,3,4- Oxadiazole N- Mannich bases: Synthesis, antimicrobial and anti-proliferative activities. Molecules2021, 26, 21102121,https://doi.org/10.3390/molecules26082110.

7. Gottwald, K.; Seebach, D. Ring-opening with a kinetic resolution of azlactones by Ti- Taddolates. Tetrahedron 1999, 55, 723-738,https://doi.org/10.1016/S0040-4020(98)01064-3.

8. Meiwes, J.; Schudock, M.; Kretzschmar, G. Asymmetric synthesis of L thienylalanines.Tetrahedron: Asymmetry1997, 8, 527-536,https://doi.org/10.1016/S0957-4166(97)00016-5.

9. Cativiela, C.; Diaz-de-Villegas, M.; Garcia, J.I.; Jimenez, A.I. 1, 3-Dipolar cycloaddition of diazomethane to chiral azlactones. Experimental and theoretical studies. Tetrahedron 1997, 53, 4479-4489.

10. Puli, V.; Kumar, V.K.; Regalla, V.R.; Chatterjee A. Microwave-assisted synthesis, characterization and biological evaluation of phenylacrylamide derivatives of triazoles derived from oxazolones. Asian Journal of Pharmaceutical Clinical Research2018, 11, 285-290,https://doi.org/10.22159/ajpcr.2018.v11i7.25689.

11. Alsharef, S.; Alanazi, M.; Alharthi, F.; Qandil, D.; Qushawy, M. Review about radiopharmaceuticals: Preparation, radioactivity and applications. International Journal of Applied Pharmaceutics2020, 12, 815,https://doi.org/10.22159/ijap.2020v12i3.37150.

12. Matsunaga, H.; Ishizuka, T.; Kunieda, T. Synthetic utility of five-membered heterocycles-chiral functionalization and applications. Tetrahedron $2005, \quad 61, \quad 8073-8094$, https://doi.org/10.1016/j.tet.2005.05.076.

13. Ellaithy, M.M.; El-Ragehy, N.A.; El- Ghobashy, M.A. Kinetic study of alkaline induced hydrolysis of the skeletal muscle relaxant chlorzoxazone using ratio spectra first derivative Spectrophotometry. Il Farmaco2003, 58, 337-342,https://doi.org/10.1016/S0014-827X(02)00026-5.

14. Goksen, U.S.; Kelekci, N.G.; Goktas, O.; Koysal, Y.; Kilic, E.; Isik, S. 1- Acylthiosemicarbazides, 1,2,4triazole-5(4H)-thiones,1,3,4-thiadiazoles and hydrazones containing 5-methyl-2-benzoxazolinones: synthesis, analgesic-anti-inflammatory and antimicrobial activities. Bioorganic Medicinal Chemistry2007, 15, 5738-5751, https://doi.org/10.1016/j.bmc.2007.06.006.

15. Dogruer, D.S.; Unlu ,S.; Sahin, M.F.; Yesilada, E. Anti-nociceptive and anti-inflammatory activity of some (2- benzoxazolone-3-yl and 2-benzothiazolone-3- yl) acetic acid derivatives. Il Farmaco1998, 53, 8084,https://doi.org/10.1016/S0014-827X(97)00017-7.

16. Pasha, M.A.; Jayashankara, V.P.; Venugopala, K.N.; Rao, G.K. Zinc Oxide (ZnO): an efficient catalyst for the synthesis of 4- arylmethylidene-2-phenyl-5-(4H)-oxazolones having antimicrobial activity. Journal of Pharmacology and Toxicology2007, 2, 264-270, https://doi.org/10.3923/jpt.2007.264.270. 
17. Schnurch, M.; Hammerle, J.; Stanetty, P.' Product class: benzoxazoles and other annulated oxazoles. In Science of Synthesis Updates, by Georg Thieme Verlag 2010, 1-54.

18. Mukesh, B.P.; Indresh, J.N.; Brindal, H.P.; Manish, K.S. Novel synthesis of 3-(((E)-benzylidene)amino)-5((Z)-3,4-dimethoxybenzylidene)-2-phenyl-3,5-dihydro-4H-imidazol-4-one derivatives as potent antimicrobial agents, World Scientific News2019,130,42-70.

19. Fawzia, F.A., Menier, A.; Arshi, N.; Zainab, M.H.; Rawda, M.O.; Tarek, H.A., Mohamed, H. Novel oxazolones incorporated azo dye: Design, synthesis photophysical-DFT aspects and antimicrobial assessments with In-silico and In-vitro surveys, Journal of Photochemistry and Photobiology2021, 7 , 100032-100048,https://doi.org/10.1016/j.jpap.2021.100032.

20. Olomola, T.O.; Akinbove, A.J.; Olasunkanmi, O.O.; Olasunkanmi, L.O. Synthesis, Antimicrobial activities and Computational studies of some Oxazolone derivatives, Ife Journal of Science2018, 20, 1-14, https://doi.org/10.4314/ijs.v20i1.1.

21. Aguirre-Rentería, S.A.; Carrizales-Castillo, J.J.; Corona, M.D.R.C.; Hernández-Fernández, E.; GarzaGonzález, E.; Rivas-Galindo, V.M.; Arredondo-Espinoza, E.; Avalos-Alanís, F.G. Synthesis and in vitro evaluation of antimycobacterial and cytotoxic activity of new $\alpha, \beta$-unsaturated amide, oxazoline and oxazole derivatives from L-serine, Bioorganic Medicinal Chemistry Letter2020, 30, 127074, https://doi.org/10.1016/j.bmcl.2020.127074.

22. Brownlee, G.; Woodbine, M. The antibacterial activity of some synthetic compounds related to penicillin. Brazilian Journal of Pharmacology1948, 3, 305-308, https://doi.org/10.1111/j.1476-5381.1948.tb00391.x.

23. Siddiqui, S.A.; Bhusare, S.R.; Jarikote, D.V.; Pawar, R.P.; Vibhute, Y.B. New novel synthesis and antibacterial activity of 1- (substituted phenyl)-2-phenyl-4-(3'-halo, 4'- hydroxy 5'-methoxy benzylidene)imidazole-5- ones. Bulletin of Korean Chemical Society2001, 22, 1033-1036.

24. Desai, N.C.; Bhavsar, A.M.; Baldaniya, B.B. Synthesis and antimicrobial activity of 5- imidazolinone derivatives. Indian Journal of Pharmaceutical Sciences2009, 71, 90-94, https://doi.org/10.4103/0250474X.51953.

25. Abdel-Aty, A.S. Pesticidal effects of some imidazolidine and oxazolone derivatives. World Journal ofAgricultural Research2009, 5,105-113.

26. Argade, N.D.; Kalrale, B.K.; Gill, C.H. A microwave-assisted improved method for the synthesis of pyrazole containing 2, 4 - disubstituted oxazole-5-one and their antimicrobial activity. European Journal of Chemistry2008, 5: 120-129,https://doi.org/10.1155/2008/265131.

27. Sanchez, C.; Mendez, C.; Salas, J.A. Indolocarbazole natural products: occurrence, biosynthesis and biological activity. Natural Product Report2006, 23, 1007-1045, https://doi.org/10.1039/b601930g.

28. Ahmed, A.F.; Raaben, M.M.; Eman, H.T.; Mamdouh, A.A.H. Synthesis and Anticancer Activity of 2-Aryl4-(4-Methoxybenzylidene)-5-Oxazolone Scaffolds, Biointerface Research in Applied Chemistry2021, 11, 8096-8109,https://doi.org/10.33263/BRIAC111.80968109.

29. Gaenzler and Corbo F. Part I. A 2 nitroimidazole indocyanine green dye derivative tumour imaging agent. Part II. A dichlorination-reductive-dechlorination route to $\mathrm{N}$-acetyl-2-oxazolone. Part III. Intramolecular Diels-Alder approach to the synthesis of pancratistatin. ProQuest and Dissertations Theses2007, AAT 3289509, 163.

30. Martinez, A.P.; Lee, W.W.; Goodman, L. Some 2-fluoroethylamines derived from hydrocinnamic acid, phenylpyruvic acid and DL-phenylalanine. Tetrahedron1964, 20, 2763-2771,https://doi.org/10.1016/S00404020(01)98494-7.

31. Gelmi, M.L.; Clerici, F.; Melis, A. 5(4H) - Oxazolones. Part X. Acid and bases effects on the translactonization reaction of 4-(2-Oxa-alkylidene)-5(4H)-oxazolones: New synthesis of 5-alkylidene-3benzoylamino-2(5H)-furanones. Tetrahedron1997, 53, 1843-1854, https://doi.org/10.1016/S00404020(96)01101-5.

32. Muhittin, A. Structural characterization and DFT studies of an oxazol-5-one derivative. Balikesir Universitesi Fen Bilimleri Enstitusu Dergisi2018, 20, 389-397,https://doi.org/10.25092/baunfbed.414333.

33. Ibrahim, H.N.; Daygu, B.C., Gul, Y.; Derya, T.; Muhittin, A.; Serap, A. Spectroscopic, Structural and Density Functional Theory (DFT) Studies of Two Oxazol-5-one Derivatives. Acta Chimica Slovenica2018, 65, 8696, https://doi.org/10.17344/acsi.2017.3613.

34. Siddiqui, I.R.; Singh, P.K.; Srivastava, V.; Singh, J. Facile synthesis of acyclic analogues of a carbocyclic nucleoside as a potential anti-HIV prodrug. Indian Journal of Chemistry2010, 49, 512520,http://hdl.handle.net/123456789/7937. 
35. Sierra, F.M.P.; Pierre, A.; Burbridge, M.; Guilbaud, N. Novel bicyclic oxazolone derivatives as antiangiogenic agents. Bioorganic \& Medicinal Chemistry Letters2002, 12, 14631466,https://doi.org/10.1016/S0960-894X(02)00197-X.

36. Madkour, H.M.F. Simple one-step syntheses of heterocyclic systems from (4Z)-2-phenyl-4- (thien-2ylmethylene)-1, 3(4H)-oxazol-5-one. Chemical Papers2002, 56, 313-319.

37. Khan, K.M.; Mughal, U.R.; Khan, M.T.H.; Ullah, Z.; Perveen, S.; Choudhary, M.I. Oxazolones: new tyrosinase inhibitors; synthesis and their structure-activity relationships. Bioorganic \& Medicinal Chemistry2006, 14, 6027-6033,https://doi.org/10.1016/j.bmc.2006.05.014.

38. Tikdari, A.M.; Fozooni, S.; Hamidian, H. Dodecatungstophosphoric acid (H3PW12O40), samarium and ruthenium (iii) chloride catalyzed synthesis of unsaturated 2-phenyl- 5(4H)-oxazolone derivatives under solvent-free conditions. Molecules2008, 13, 3246-3252,https://doi.org/10.3390/molecules13123246.

39. Eman, A.G.; Naglaa, F.H.M.; Eman, A.E.E. Syntheis, DFT and eco-friendly insecticidal activity of some Nheterocycles derived from 4-((2-oxo-1,2-dihydroquinolin-3-yl)methylene)-2-phenyloxazol-5(4H)one.Bioorganic Chemistry, 2021, 112, 104945,https://doi.org/10.1016/j.bioorg.2021.104945.

40. Marian, P. Spectral characterization of oxazol-5(4H)-ones containing a furan and/or benzene ring in conjugation with the azlactone system. Journal of Chemical Research2005, 12, 766771,https://doi.org/10.3184/030823405775147031.

41. Mesaik, M.A.; Rahat, S.; Khan, K.M.; Ullah, Z.; Choudhary, M.I.; Murad, S. Synthesis and immunomodulatory properties of selected oxazolone derivatives. Bioorganic \& Medicinal Chemistry 2004, 12, 2049-2057,https://doi.org/10.1016/j.bmc.2004.02.034.

42. Taile, V.; Hatzade, K.; Gaidhane, P.; Ingle, V. Synthesis and Biological activity of 4-(4-hydroxybenzylidene)2-(substituted styryl) oxazol-5-ones and their o-glucosides. Turkish Journal of Chemistry2009, 33, 295-305, https://doi.org/10.3906/kim-0712-12.

43. Mariappan, G.; Saha, B.P.; Datta, S.; Kumar, D.; Haldar, P.K. Design, synthesis and antidiabetic evaluation of oxazolone derivatives. Journal of Chemical Sciences2011, 123, 335341,https://www.ias.ac.in/article/fulltext/jcsc/123/03/0335-0341.

44. Calbo, J.; Weston, C.E.; White A.J.P.; Rzepa, H.S.; Contreras-Garcia, J.; Fuchter, M.J. Tuning Azoheteroarene Photoswitch Performance through Heteroaryl Design, Journal of American Chemical Society2017, 139, 1261-1274,https://doi.org/10.1021/jacs.6b11626.

45. Park, J.; Lee, J.; Lee, M. 020 Type 2 immunity mediated by CD301b+ dermal dentritic cells plays a critical role in oxazolone-induced contact hypersensitivity.Journal of Investigative Dermatology2019,139, S218,https://doi.org/10.1016/j.jid.2019.07.023.

46. Dixit, A.; Garg, G.; Sharma, N.P.; Shrivastava, D.K.; Sharma, A. Synthesis \& Biological evaluation of Oxazolone derivatives. Current Research in Pharmaceutical Sciences2011, 2, 86-91.

47. Hanan, A.A.; Abdulbari, M.M. Synthesis, Characterization and Insilico Study of New 1,3- Oxazolone-5- (4$\mathrm{Cl}$ )-one and - Oxazolone-5-(4-NO2)-one Derivatives. IOP Conference Series: Material Science and Engineering 2019, 517, 012083.

48. Pallavi, L.P. Synthesis of different $\alpha, \beta$ unsaturated oxazolone derivatives. Journal of Drug Delivery \& Therapeutics2019, 9, 124-127, https://doi.org/https://doi.org/10.22270/jddt.v9i1.2189.

49. Fearnley, S.P.; Market, E. Intramolecular Diels-Alder reactions of N-substituted oxazolones. Chemical Communications 2002, 2002, 438-439, https://doi.org/10.1039/b110992h.

50. Rahim, F.; Tariq, S.; Taha, M.; Ullah, H.; Zaman, K.; Uddin, I.; Wadood, A.; Khan, A.A.; Rehman, A.U.; Uddin, N.; Zafar, S. New triazinoindole bearing thiazole/oxazole analogues: Synthesis, $\alpha$-amylase inhibitory potential and molecular docking study. Bioorganic Chemistry2019, 92, 103284, https://doi.org/10.1016/j.bioorg.2019.103284.

51. Samantha, C.; Simona, D.M.; Vincenzo, C.; Piero, T.; Marco, M.; Debora, R.; Ilaria, P.; Maria, S.; Sine, M.B.; Natalia, R.; Natasha, M.; Marco, M.; Giuliana, O.; Min, L.; Peter, L.; Andrea, A.; Rosalia, B.; Soumya, S.R.; Renato, S.; Rita, S. Design, Synthesis and Biological Evaluation of a Series of Oxazolone Carboxamides as a Novel Class of Acid Ceramidase Inhibitors.Journal of Medicinal Chemistry, 2020, 63, 15821-15851, https://doi.org/10.1021/acs.jmedchem.0c01561.

52. Jonathan, C.; Veronica, E.S.; Laura, M.K.D. The enzymology of oxazolone and thioamide synthesis in methanobactin.Methods in Enzymology2021, https://doi.org/10.1016/bs.mie.2021.04.008.

53. Vijaya, P.; Sundaraselvan, G. Synthesis, characterization, PASS analysis and ADMET properties of oxazolone ring containing hydrazone derivatives.Materials Today2021, https://doi.org/10.1016/j.matpr.2021.03.130. 
54. Teng, F.; Chenghui,S.; Siping, P. A comparative study of bridged 1, 2, 4-oxazolones and their derivatives.Energetics Material Frontiers, 2020, 1, 26-33,https://doi.org/10.1016/j.enmf.2020.06.001.

55. Marra,I.F.S.; De Castro, P.P.; Amarante, G.W. Recent advances in azlactone transformation.European Journal of Organic Chemistry, 2019, 2019, 5830-5855,https://doi.org/10.1002/ejoc.201901235.

56. Bourotte, M.; Schmitt, M.; Wund, A.F.; Pigault, C.; Haiech, J.; Bourguignon, J.J. Fluorophores related to the green fluorescent protein. Tetrahedron Letters2004, 45, 63436348,https://doi.org/10.1016/j.tetlet.2004.06.072.

57. Ozturk, G.; Alp, S.; Timur, S. Photophysical characterization of fluorescent oxazol-5-one derivatives in PVC and their application as biosensors in the detection of ACh and AChE inhibitor: donepezil. Dyes and Pigments2008, 76, 792-798,https://doi.org/10.1016/j.dyepig.2007.02.005.

58. Nagaraju, K.; Lalitha, G.; Suresh, M.; Kranthi, K.G.; Sreekantha, B.J. A Review on Recent Advances in Nitrogen-Containing Molecules and Their Biological Applications.Molecules2020, 25, 1909-1951, https://doi.org/10.3390/molecules25081909.

59. Trivedi, V.; Shah, S.H. Synthesis, characterization and antibacterial screening of some novel biphenyl-4carboxylic acid (4-benzylidene- 5-oxo-2-subsituted phenyl-4, 5-dihydro-imidazol-1-yl)-amide.Oriental Journal of Chemistry2009, 25, 893-899.

60. Muthuboopathi, G.; Shanmugarajan, T.S. Synthesis, characterization and biological evaluation of oxazolone analogues. Asian Journal of Pharmaceutical and Clinical Research2018, 11, 159162,https://doi.org/10.22159/ajpcr.2018.v11s4.31726.

61. Abdel-Aty, A.S. Pesticidal effects of some imidazolidine and oxazolone derivatives. World Journal of Agricultural Sciences2009, 5, 105-113,http://www.idosi.org/.../16.pdf.

62. Haneen, D.S.A.; Wael, S.I.A.; Youssef, A.S.A. 5(4H)-oxazolones: Synthesis and biological activities.Synthetic Communications, 2020, 215-233,https://doi.org/10.1080/00397911.2020.1825746.

63. El-Mekabaty, A. Erlenmeyer Azlactones: Synthesis, Reactions and Biological Activity. ChemInform 2013, 44, 40-66, https://doi.org/10.1002/chin.201334216.

64. Fearnley, S.P.; Market, E. Intramolecular Diels-Alder reactions of N-substituted oxazolones. Chemical Communications 20022002: 438-439, https://doi.org/10.1039/b110992h.

65. Avenoza, A.; Busto, J.H.; Cativiela, C.; Peregrina, J.M. Reactivity of (Z)-4-arylidene- 5(4H)-oxazolones: [4+2] cycloaddition versus [4+3] cycloaddition/nucleophilic trapping. Tetrahedron Letters2002, 43, 41674170,https://doi.org/10.1016/S0040-4039(02)00744-X.

66. Canan, K.; Ezgi, U.; Nurten, A. A Research for some oxazolidinones to evaluate their antimicrobial activity. Journal of Faculty of Pharmacy of Ankara University 2018, 42, 32-37, https://doi.org/10.1501/Eczfak_0000000610.

67. Wasim Akram, M.A.; Lakshmi, S.; Shankar, B.; Gouda, S.T. Synthesis, Characterization and Biological Evaluation of Oxazolone Derivatives. International Journal of Pharmaceutical Research2014, 3, 775-779.

68. Hooshang, H.; Ahmad, M.T. Novel synthesis of unsaturated 5(4H)-oxazolone derivatives with using Palladium (II) acetate as a catalyst and microwave irradiation in solvent-free condition. Heterocyclic Communications 2006, 12, 29-34,https://doi.org/10.1515/HC.2006.12.1.29.

69. Herbst, R.M.; Shemin, D. "Organic synthesis"Coll., II, Wiley, New York 1943, 1.

70. Carter, H.E. A review of the synthesis "Organic Reactions", III, Wiley, New York, 1946, 198.

71. Synder, H.R.; Buck, J.S.; Ide, W.S. "Organic Synthesis"Coll., II, Wiley, New York, 1943, 333.

72. Naganagowda, G.; Petsom, A. Synthesis and Antimicrobial Activity of Oxazolone, Imidazolone and Triazine Derivatives Containing Benzothiophene. Bulletin of the Korean Chemical Society2011, 32, 39143922,https://doi.org/10.5012/bkcs.2011.32.11.3914.

73. Shahnawaaz, M.; Naqvi, A.; Rao, A.V.; Seth, D.S. Design and Synthesis of substituted oxazolones and their antibacterial activity. International Electronic Conference on Synthetic Organic Chemistry2009, 13, 1-30.

74. Pasha, M.A.; Jayashankara, V.P.; Venugopala, K.N.; Rao, G.K. Zinc Oxide (ZnO): an efficient catalyst for the synthesis of 4- arylmethylidene-2-phenyl-5-(4H)-oxazolones having antimicrobial activity. Journal of Pharmacology and Toxicology2007, 2, 264-270, https://doi.org/10.3923/jpt.2007.264.270.

75. Rao, Y.S. Recent advances in the chemistry of unsaturated lactones. Chemical Reviews1976, 76, 625694,https://doi.org/10.1021/cr60303a004.

76. Lamia, W.M.; El-Badry, O.M.; El-Ansary, A.K.; Ismael, A. Design \& synthesis of novel oxazolone \& triazinone derivatives and their biological evaluation as COX-2 inhibitors. Bioorganic Chemistry2017, 72, 308-314,https://doi.org/10.1016/j.bioorg.2017.04.012. 
77. Catarina, A.B.R.; Ines, F.A.M.; Ermelinda, M.S.M.; Carlos, A.M.A. Two-photon absorption properties of push-pull oxazolones derivatives. Dyes and Pigments2012, 95, 713722,https://doi.org/10.1016/j.dyepig.2012.06.005.

78. Fahmy, A.F.M.; El-Sayed, A.A.; Hemdan, M.M. Multicomponent synthesis of 4-arylidene-2-phenyl-5 (4H) oxazolones (azlactones) using a mechanochemical approach. Chemistry Central Journal2016, 10, 1-7, https://doi.org/10.1186/s13065-016-0205-9.

79. Nagamani, C.; Basavarajaiah, S.M.; Nagaraj, S.; Saraswathi, D.C. Synthesis, Characterization and Biological Evaluation of Oxazolone Derivatives. International Journal of Computer Engineering Research2016, 6, 3134.

80. Sharada, L.N.; Aparna, Y.; Saba, M.; Sunitha, S.N.T.; Viveka, L. A Review on Reactions and Applications of Oxazolones. International Journal of Scientific and Research Publication2015, 5, 1-9.

81. Kildisheva, O.V.; Linkova, M.G.; Knunyants, I.L. Structure and properties of oxazolones. Russian Chemical Bulletin1957, 6, 737-747, https://doi.org/10.1007/bf01167225.

82. Kagan, Z.S. Synthesis of $\alpha$-keto acids via azlactones of 2-(acylamino)-3-alkyl (or aryl) acrylic acids, and a new synthesis of 3-methyl-2-oxovaleric acid. Russian Chemical Bulletin1957, 6, 1508-1510, https://doi.org/10.1007/bf01169758.

83. Iwakura, Y.; Toda, F.; Torii, Y. A novel preparation of pseudoxazolones, Tetrahedron1967, 23, 33633373,https://doi.org/10.1016/S0040-4020(01)92303-8.

84. Minmi, J.; Sun-Woo,W.; Dong, G.L.; Jungeon, Y.; Sunhong, K.; Young-Shin, K. Facile ring-opening reaction of oxazolone enables efficient amidation for aminoisobutyric acid. Archives of Pharmaceutical Research2018, 41, 481-489, https://doi.org/10.1007/s12272-018-1031-5.

85. Osman, M.O.; Habib, H.M.; Evelin, B.M., El-Mekabaty, A. Reactivity of Oxazolone Derivative towards Nitrogen and Carbon Nucleophilic Reagents: Applications to the Synthesis of New Heterocycles. International Journal of Modern Organic Chemistry2013, 2, 11-25.

86. Aaglawe, M.J.; Dhule, S.S.; Bahekar, S.S.; Wakte, P.S.; Shinde, D.B. Synthesis and Antibacterial Activity of Some Oxazolone Derivatives. Journal of Korean Chemical Society 2003, 47, 133-136, https://doi.org/10.5012/jkcs.2003.47.2.133.

87. Ahmed, S.A. Pesticidal effects of Some Imidazolidine and Oxazolone Derivatives. World Journal of Agricultural Sciences2009, 5, 105-113,http://www.idosi.org/.../16.pdf.

88. Baltork, M.; Moghadam, M.; Tangestaninejad, S.; Mirkhani, V.; Zolfigol, M.; Hojati, S. Silica Sulfuric AcidCatalyzed Synthesis of Benzoxazole, Benzimidazoles and Oxazolo [4, 5-b] pyridines Under Heterogeneous and Solvent-Free Conditions. Journal of Iranian Chemical Society2008, 5, 65-70.

89. Tandel, R.C. Synthesis and Study of Oxazolone Derivatives Showing Biological Activity. Research Journal of Pharmaceutical Sciences2012, 1, 1-5.

90. Somila, K.; Sarveswari, S.; Gupta, R.; Vijayakumar, V. Synthesis and biological evaluation of some pyridazinone derivatives. International Journal of Research in Pharmacy and Chemistry 2012, 2, 258-266.

91. Foye, W.O.; Lemke, T.L.; Williams, D.A. Principles of Medicinal Chemistry, 4th Ed., Williams and Wilkins. London 1995; 345-387, 499-534.

92. Sotelo, E.; Fraiz, N.; Yanez, M.; Laguna, R.; Cano, E.; Ravina, E. Pyridazines. Part 31: Synthesis and antiplatelet activity of 4, 5-disubstituted-6-phenyl 3(2H)-pyridazinones. Chemical and Pharmaceutical Bulletin2002, 50, 1574-77.

93. Fozooni, S.; Khoshdast, H.; Hassani, H.; Hamidian, H. Synthesis of Oxazolone and Imidazolone Derivatives in the Presence of H2O2 Promoted Fly Ash as a Novel and Efficient Catalyst. Journal of Sciences, Islamic Republic of Iran2017, 28, 221 - 230.

94. Frank, H.S. The action of hydrazine hydrates on oxazolone. Journal of Organic Chemistry1948, 13, 757762,https://doi.org/10.1021/jo01163a023.

95. Mariappan, G.; Saha, B.P.; Datta, S.; Kumar, D.; Haldar, P.K. Design, synthesis and antidiabetic evaluation of oxazolone derivatives. Journal of Chemical Sciences 2011, 123, 335-341,https://doi.org/10.1007/s12039011-0079-2.

96. Jat, L.R.; Mishra, R.; Pathak, D. Synthesis and anticancer activity of 4-Benzylidene-2-phenyloxazol-5(4H) one derivatives. International Journal of Pharmacy and Pharmaceutical Sciences 2012, 4, 378-380.

97. Awad, W.I.; Fawn, A.K.; Zayed, M.A. Studies on 2- Phenyl-4-arylidene-5-oxazolones. Tetrahedron1964, 20, 891-896,https://doi.org/10.1016/S0040-4020(01)98422-4.

98. Petrov, O., Ivanova, Y.; Momekov, G.; Karaivanova, M.; Kalcheva, V. Cytotoxic Mannich bases of 6-(3aryl-2-propenoyl)-2(3H)-benzoxazolones. European Journal of Medicinal Chemistry2007, 42, 1382-1387. 
99. Sumana, Y.K.; Abishad, P.M.; Byrappa, K.; Rai, K.M.L. Novel series of 1, 3, 4- Oxadiazole derivatives: Evaluation of Thermal properties and Antibacterial activity. Letters in Applied NanoBioScience2021, 10, 2370-2381,https://doi.org/10.33263/LIANBS103.23702381.

100.Mulwad, V.V.; Satwe, D.S. Synthesis of biologically active 4-[1-(2H-[1]-4-hydroxy-2-oxo-benzopyran-3-yl) methylidene]-2-phenyl-4H-oxazol-5-ones and [1, 2, 4] triazine-6-one and its derivatives. Indian Journal of Chemistry2006, 45, 1210-1215,http://hdl.handle.net/123456789/30694.

101.Doru, R. Synthesis, characterization, structural analysis and reactivity of $5(4 \mathrm{H})$-oxazolone derivatives and rotaxane precursors, PhD Thesis, University of Zaragoza2009, 1-53.

102.Jason, S.F.; Robert, A.M.; Jetze, J.T. The diverse chemistry of oxazol-5-(4H)-ones. Chemical Society Reviews 2007, 36, 1432-1440, https://doi.org/10.1039/b511113g.

103.Manasi, K.; Jetze, J.T. One-Pot Friedel-Crafts/Robinson-Gabriel Synthesis of Oxazoles Using Oxazolone Templates. Journal of Organic Chemistry2005, 70, 4211-4213, https://doi.org/10.1021/jo0501590.

104. Sharma, N.; Banerjee, J.; Shrestha, N.; Chaudhury, D. A review on oxazolone, it's a method of synthesis and biological activity. European Journal of Biomedical and Pharmaceutical Sciences2015, 2, 964-987.

105.Nagaraja, O.; Yadav, D.B.; Itte, P.; Kumar, S.R. Synthesis, characterization and biological investigation of potentially bioactive heterocyclic compounds containing 4-hydroxy coumarin. Heliyon 2020, 6, 42454255,https://doi.org/10.1016/j.heliyon.2020.e04245.

106.Nadia, G.K.; Howida, T.Z.; Mansoura, I.M. Efficient synthesis of new oxindol-based heterocyclic entities via indolin-2-one derivatives. Arabian Journal of Chemistry2014, 7, 630638,https://doi.org/10.1016/j.arabjc.2014.01.005.

107.Bentley, T.W.; Llewellyn, G.; McAlister, J.A. SN2 Mechanism for Alcoholysis, Aminolysis and Hydrolysis of acetyl chloride. Journal of Organic Chemistry 1996, 61, 7927-7932,https://doi.org/10.1021/jo9609844.

108.Ignatius, J.T.; Michael, J.S.D. Chemistry of Oxazoles. Chemical Reviews1975, 75, 389437,https://doi.org/10.1021/cr60296a002.

109.Robert, F.; James, W. Notes- Chemistry of unsaturated lactone I. Reaction of oxazolones with Phenylmagnesium Bromide. Journal of Organic Chemistry1957, 22, 853855,https://doi.org/10.1021/jo01358a623.

110.Edward, G.B.; Charles, H.S. Stereoselective formation of a pseudo oxazolone. Journal of Organic Chemistry1974, 39, 1311-1312,https://doi.org/10.1021/jo00923a033.

111.Filler, R.; Rao, Y.S. Chemistry of Lactones. VI. The reaction of Unsaturated Azlactones under Friedel-Crafts Conditions. Journal of Organic Chemistry 1962, 27, 2403-2406,https://doi.org/10.1021/jo01054a029.

112. Abeer, N.A.R. Synthesis and antitumor activity of new isolated and fused heterobicyclic nitrogen system containing 1, 3, 4-thiadiazole moiety derived from N1, N2-diaryl hydrazine compound. Letters in Applied NanoBioScience 2020, 9, 885-891,https://doi.org/10.33263/LIANBS91.885891.

113. Cativiela, C.; Díaz-de-Villegas, M.D. The Chemistry of Heterocyclic Compounds; Wiley: New York; Palmer, D. C. Ed. 2004, 60, 129-330.

114.Rahman, S.Z.S.; Jetze, J.T. Synthesis of 1, 2, 4-Triazolines and Triazoles Utilizing Oxazolones. Journal of Organic Chemistry 2010, 75, 4330-4332, https://doi.org/10.1021/jo100716m.

115.David, I.C.; Laura, H.; Mark, L. Synthesis of 2-Oxazolones and $\alpha$-Aminoketones via Palladium-Catalyzed Reaction of $\beta$, $\beta$-Dibromoenamides. Organic Letters2011, 13, 106-109,https://doi.org/10.1021/ol102634c.

116.Arya, K.M.; Rao, L.; Homami, S.S.; Joseph, K. Reaction of unsaturated azlactones with sulfur nucleophiles: some observations. Canadian Journal of Chemistry1994, 72, 1383-1387, https://doi.org/10.1139/v94-173.

117.Xinjia, Y.; Jing, W.; Lin, Z.; Lei, F.; Xiaobo, W.; Zhi, X. Current Scenario of 1, 3- oxazole derivatives for Anticancer Activity. Current Topic in Medicinal Chemistry2020, 21, 1916-1937, https://doi.org/10.2174/1568026620666200624161151.

118.Richard, H.W.; Leonard, L.B. The Chemistry of the Oxazolines. Chemical Reviews1949, 44, 447476,https://doi.org/10.1021/cr60139a002.

119.Xunan, Z.; Wei, L.; Dawei, Z. Recent Advances in the Synthesis of Oxazole-Based Molecules via van Leusen Oxazole Synthesis. Molecules2020, 25, 1594-1611, doi:10.3390/molecules25071594.

120.Anthi, P.; Maria, F.; Athina, G. Thiazole Ring- A biologically active scaffold. Molecules2021, 26, 31663240,https://doi.org/10.3390/molecules26113166.

121.Muxfeldt, H.; Schneider, R.S. Formation of derivatives of cyclopentane-1, 3-dione from oxazolones. Journal of Organic Chemistry1968, 33, 1645-1647,https://doi.org/10.1021/jo01268a074.

122.Islam, A.M.; Khalil, A.M.; El-Gawad, A. II. Synthesis of 2-aryl-4-phthalidyliden-1, 5, 3-oxazolin-5-ones. Chemicke Zvesti 1974, 28, 606-667. 
123.Pratibha, B.A.; Kailas, G.B. Diverse Heterocyclic Ring Systems: Innovative Advances in Medicinal Chemistry, Mini-Review in Medicinal Chemistry2021, 21, 134, https://doi.org/10.2174/138955752102201221150306.

124.Kamneva, I.E.; Anis kova, T.V.; Egorova, A.Y. Arylmethylidenefuranones: Reactions with C- and Nnucleophiles. Research Journal of Chemistry2018, 8, 183-196.

125.Sharma, P.K.; Amin, A.; Kumar, M. Synthetic Methods of Medicinally Important Heterocyclic-thiazines: A Review. The Open Medicinal Chemistry Journal2020, 14, 71-82, https://doi.org/10.2174/1874104502014010071. 